\title{
Angiotensin II-accelerated atherosclerosis and aneurysm formation is attenuated in osteopontin-deficient mice
}

\author{
Dennis Bruemmer, ${ }^{1,2}$ Alan R. Collins, ${ }^{1}$ Grace Noh, ${ }^{1}$ Wei Wang, ${ }^{1}$ Mary Territo, ${ }^{3}$ \\ Sarah Arias-Magallona, ${ }^{3}$ Michael C. Fishbein, ${ }^{4}$ Florian Blaschke, ${ }^{1,2}$ Ulrich Kintscher, ${ }^{2}$ \\ Kristof Graf, ${ }^{2}$ Ronald E. Law, ${ }^{1}$ and Willa A. Hsueh ${ }^{1}$ \\ ${ }^{1}$ Division of Endocrinology, Diabetes and Hypertension, and The Gonda (Goldschmied) Diabetes Center, \\ David Geffen School of Medicine, University of California, Los Angeles, Los Angeles, California, USA \\ ${ }^{2}$ Department of Medicine/Cardiology, German Heart Institute, Berlin, Germany \\ ${ }^{3}$ Division of Hematology and Oncology, and \\ ${ }^{4}$ Department of Pathology, David Geffen School of Medicine, University of California, Los Angeles, California, USA
}

\begin{abstract}
Osteopontin (OPN) is expressed in atherosclerotic lesions, particularly in diabetic patients. To determine the role of $\mathrm{OPN}$ in atherogenesis, $\mathrm{ApoE}^{-/-} \mathrm{OPN}^{+/+}, \mathrm{ApoE}^{-/-} \mathrm{OPN}^{+-}$, and $\mathrm{ApoE}^{-/-} \mathrm{OPN}^{-/-}$mice were infused with Ang II, inducing vascular OPN expression and accelerating atherosclerosis. Compared with $\mathrm{ApoE} \mathrm{E}^{-/-} \mathrm{OPN}^{+/+}$mice, $\mathrm{ApoE} \mathrm{E}^{-/-} \mathrm{OPN}^{+/-}$and $\mathrm{ApoE}^{-/-} \mathrm{OPN}^{-/-}$mice developed less Ang II-accelerated atherosclerosis. $A \mathrm{poE}^{-/-}$mice transplanted with bone marrow derived from $A \mathrm{PoE}^{-/-} \mathrm{OPN}^{-/-}$mice had less Ang II-induced atherosclerosis compared with animals receiving $\mathrm{ApoE}^{-/-} \mathrm{OPN}^{+/+}$cells. Aortae from Ang II-infused $A \mathrm{poE}^{-/-} \mathrm{OPN}^{-/-}$mice expressed less CD68, C-C-chemokine receptor 2, and VCAM-1. In response to intraperitoneal thioglycollate, recruitment of leukocytes in $\mathrm{OPN}^{-/-}$mice was impaired, and $O P N^{-/-}$leukocytes exhibited decreased basal and MCP-1-directed migration. Furthermore, macrophage viability in atherosclerotic lesions from Ang II-infused $\mathrm{ApoE}^{-/-} \mathrm{OPN}^{-/-}$mice was decreased. Finally, Ang II-induced abdominal aortic aneurysm formation in $\mathrm{ApoE}^{-/-} \mathrm{OPN}^{-/-}$mice was reduced and associated with decreased MMP-2 and MMP-9 activity. These data suggest an important role for leukocytederived OPN in mediating Ang II-accelerated atherosclerosis and aneurysm formation.
\end{abstract}

J. Clin. Invest. 112:1318-1331 (2003). doi:10.1172/JCI200318141.

\section{Introduction}

Osteopontin (OPN) is a secreted ECM protein with pleiotropic functions that have been implicated in tissue repair, remodeling, and inflammation $(1,2)$. Although OPN was first isolated from bone where it mediates the adhesion of osteoclasts to the mineralized matrix (3-5), subsequent studies have demonstrated that OPN is expressed in a variety of other tissues. OPN has been identified as a prominent component of human atherosclerotic lesions where it is synthesized by cells of the monocyte/macrophage lineage and to a lesser extent by endothelial cells (ECs) and VSMCs (6). In particular, OPN expression is

Received for publication February 17, 2003, and accepted in revised form August 26, 2003.

Address correspondence to: Willa A. Hsueh, Division of Endocrinology, Diabetes and Hypertension, David Geffen School of Medicine, University of California, Los Angeles, Warren Hall, Suite 24-130, 900 Veteran Avenue, Los Angeles,

California 90095, USA. Phone: (310) 794-7555;

Fax: (310) 794-7654; E-mail: whsueh@mednet.ucla.edu.

Conflict of interest: The authors have declared that no conflict of interest exists.

Nonstandard abbreviations used: osteopontin (OPN); endothelial cell (EC); arginine-glycine-aspartate (RGD); reninangiotensin system (RAS); abdominal aortic aneurysm (AAA); OPN-null mutant mice $\left(\mathrm{OPN}^{-/-}\right)$; ApoE receptor-deficient mice $\left(A p o E^{-/-}\right)$; elastin van Gieson (EVG); monocyte chemoattractant protein-1 (MCP-1); C-C-chemokine receptor-2 (CCR-2); reverse transcription (RT); high-power field (HPF); white blood cell (WBC) increased by high glucose levels in arteries of diabetic patients and thus has been implicated in the pathogenesis of diabetic nephropathy, atherosclerosis, and other diabetic vascular complications $(7,8)$.

OPN has dual functions, acting as an ECM protein and a proinflammatory cytokine $(1,2)$. Containing an arginine-glycine-aspartate-binding (RGD-binding) motif (4), OPN binds to several cell-surface integrins $(9,10)$, whereas engagement of the homing receptor CD44 occurs through the non-RGD cell-binding domain of OPN (11). OPN receptor interactions mediate important cellular-signaling pathways, allowing OPN to promote cell adhesion and motility and thus contribute to diverse processes such as cell growth (12), migration $(13,14)$, inflammation, and tissue remodeling (15). In addition, OPN can function as a chemotactic cytokine, regulating immune cell function and promoting the adhesion, migration, and activation of macrophages $(14,16,17)$.

Inflammatory processes and macrophage activation are integral to atherosclerosis development (18). Transendothelial migration of monocytes into the subendothelial interstitium, their differentiation into macrophages, and accumulation of these macrophages in the arterial wall are crucial early events (19). Evolution of the disease involves LDL-cholesterol uptake and oxidation in the vascular wall leading to development of cholesterol-loaded macrophages that form fatty streaks in the neointima (20). 
Ang II profoundly induces OPN expression in the arterial wall (21). Activation of the renin-angiotensin system (RAS) is a common feature in patients with the metabolic syndrome and type 2 diabetes, who have a fourfold higher risk for the development of atherosclerosis (22-24). Moreover, infusion of Ang II into atherosclerosis-prone mice substantially accelerates the atherosclerotic process leading to the development of extensive atherosclerotic plaque formation and abdominal aortic aneurysms (AAA) (25-27). To elucidate the role of OPN in the pathogenesis of accelerated atherosclerosis, we crossed OPN-null mutant mice $\left(\mathrm{OPN}^{-/-}\right)$ into the atherosclerosis-prone ApoE receptor-deficient $\left(A p o E^{-/-}\right)$background and infused these mice with Ang II. Using two different models, Ang II acceleration of atherosclerosis in either $A p o E^{-/-} O P N^{-/-}$mice or irradiated $A \mathrm{POE}^{-/-}$mice receiving bone marrow transplants from $A p o E^{-/-} \mathrm{OPN}^{-/-}$mice, we demonstrate that OPNdeficient leukocytes provide substantial protection against Ang II-accelerated atherosclerosis and AAA formation. The mechanisms by which OPN contributes to vascular pathology in this model involves the recruitment of leukocytes, increase of their viability, and an induction of cytokine and MMP expression.

\section{Methods}

Generation of mice. OPN $\mathrm{N}^{-/-}$mice with a targeted mutagenesis of the secreted phosphoprotein $1(s p p-1)$ gene on a Black Swiss background were a generous gift from C.M. Giachelli (University of Washington, Seattle, Washington, USA) and Lucy Liaw (Maine Medical Center Research Institute, South Portland, Maine, USA) (15). The $A \mathrm{poE}^{-/-}$mice on a C57BL/6J background were obtained from The Jackson Laboratory (Bar Harbor, Maine, USA). Double knockout $A p o E^{-/-} \mathrm{OPN}^{-/-}$mice were generated by crossing $\mathrm{OPN}^{-/-}$mice with $A p o E^{-/-}$ mice. The $\mathrm{F}_{1}$ generation was backcrossed with $A p o E^{-/-}$ mice to fix the $A \mathrm{poE}^{-/-}$genotype, and littermates were crossed. Genotypes were confirmed by PCR, and all experiments were performed with generations $\mathrm{F}_{4}-\mathrm{F}_{6}$ using littermate $\mathrm{ApoE} \mathrm{E}^{-/-} \mathrm{OPN}^{+/+}$as wild-type controls. Animals were group housed in open-topped cages under a 12-hour light and 12-hour dark regimen and placed on a normal chow diet (diet 8604; Harlan Teklad Laboratory, Madison, Wisconsin, USA).

Atherosclerotic lesion analysis and quantification of AAAs. Two different atherosclerosis models were employed to assess the effect of OPN deficiency on atherosclerosis development in $A p o E^{-/-}$mice: Ang II infusion, which substantially accelerates atherosclerotic lesion and AAA formation (25-27), and atherosclerosis development on a normal chow diet in 8-month-old mice. Three-month-old male $A p o E^{-/-} \mathrm{OPN}^{+/+}$littermate control mice $(n=9), A p o E^{-/-} \mathrm{OPN}^{+/-}(n=9)$ mice, and $A p o E^{-/-} \mathrm{OPN}^{-/-}$mice $(n=6)$ on a normal chow diet were infused with $2.5 \mu \mathrm{g} / \mathrm{kg} / \mathrm{min}$ Ang II (Calbiochem, San Diego, California, USA) for 4 weeks for atherosclerosis analysis and for 2 weeks for mRNA analysis. Ang II was dissolved in sterile saline and infused using
Alzet osmotic minipumps (DURECT Corp., Cupertino, California, USA). Osmotic minipumps were placed subcutaneously in the dorsal midline. The dosage for each animal was determined individually at the time of implantation. Since previous studies have shown that Ang II infusion promotes the development of AAA (25-27), only the thoracic aorta was analyzed for Sudan IV staining of lipid content. In addition to the Ang II-accelerated atherosclerosis model, development of atherosclerotic lesions in the total aorta was analyzed in 8-month-old male

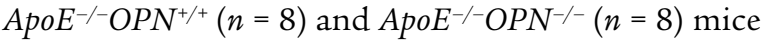
fed a normal chow diet. En face lesion analysis was performed in both models by Sudan IV staining as described previously (28). The extent of atherosclerosis was represented as the mean percentage of the thoracic aortic surface area covered by lesions.

To determine the effect of OPN deficiency on Ang IIinduced aneurysm formation, we quantified their percentage of incidence and measured their sizes $(26,29)$. Mice in which the increase in aortic diameter was less than $10 \%$ were not considered to have an aneurysm. All animal protocols were approved by the UCLA Animal Research Committee and complied with all federal, state, and institutional regulations.

Blood pressure and metabolic measurements. Blood pressures were obtained from the mice using a noninvasive tail-cuff system (BP-2000 Blood Pressure Analysis System; Visitech Systems, Apex, North Carolina, USA) as described previously (28). Blood samples were obtained from the mice before beginning Ang II infusion and at sacrifice. The blood was collected after an overnight fast from the retro-orbital plexus under isoflurane anesthesia or from the abdominal vena cava at sacrifice. Plasma glucose was measured by glucose oxidase reaction (Beckman Glucose Analyzer 2; Beckman Instruments Inc., Fullerton, California, USA). A single technician blinded to the study groups performed the measurements. Plasma lipids were measured by the UCLA Lipid Analysis Laboratory as described previously (30).

Histology and immunohistochemistry. For histological analysis mice were perfused with $4 \%$ phosphatebuffered formaldehyde. Aortic tissue was harvested, and the ascending aorta, the thoracic aorta, and the abdominal aorta were embedded in OCT (Tissue-Tek; Miles Inc., Elkhart, Illinois, USA) and snap-frozen. Transverse cryosections (10 $\mu \mathrm{m}$ thick) were collected from the ascending and abdominal aorta, fixed in cold acetone, and stained with hematoxylin and eosin, Mallory's elastin trichrome staining, or elastin van Gieson (EVG) staining. Immunohistochemical analysis of atherosclerotic lesions of the ascending and thoracic aorta were performed as described previously (28). Macrophages were detected using adsorbed rabbit anti-mouse macrophage antisera (1:10,000 dilution; Accurate Chemical \& Scientific Corp., Westbury, New York, USA), and T lymphocytes were detected using a rabbit anti-mouse anti-CD-3 $\mathrm{mAb}$ (1:50 dilution; Calbiochem). 
Bone marrow transplantation. To induce bone marrow aplasia, 8-week-old male $A p o E^{-/-}$receptor-deficient mice were exposed to total-body irradiation ( $9 \mathrm{mGy}$ ). Bone marrow cell suspensions were isolated by flushing the femurs and tibias from either $A p o E^{-/-} O P N^{-/-}$or $A p o E^{-/-} O P N^{+/+}$mice. Bone marrow cell suspensions $\left(1.5 \times 10^{7}\right)$ were injected intravenously within 1 hour after irradiation. After transplantation, the mice were placed on a regular chow diet for 4 weeks followed by infusion of $2.5 \mu \mathrm{g} / \mathrm{kg} / \mathrm{min}$ Ang II for 4 weeks.

Reverse transcription and quantitative real-time RT-PCR. OPN, CD68, monocyte chemoattractant protein-1 (MCP-1), C-C-chemokine receptor-2 (CCR-2), IFN- $\gamma$, IL-10, and IL-12 mRNA expression in the thoracic aorta was measured by real-time RT-PCR $(n=6$ for each analyzed group). Total RNA of the thoracic aorta was isolated 2 weeks after Ang II infusion using RNAzol (Tel-Test Inc., Friendswood, Texas, USA). After DNase digestion using DNA-free (Ambion Inc., Austin, Texas, USA), $500 \mathrm{ng}$ of total RNA was reverse transcribed into cDNA using TaqMan Reverse Transcription (RT) Reagent Kit (Applied Biosystems, Foster City, California, USA). Using DNA digestion and -RT reactions without reverse transcriptase, the amount of contaminating DNA was negligible. PCR reactions were performed with an ABI-PRISM 7700 system (Applied Biosystems) in a total volume of $25 \mu \mathrm{l}$, using a TaqMan PCR Core Reagent Kit (Applied Biosystems) under the following conditions: 2 minutes at $50^{\circ} \mathrm{C}$ and $10 \mathrm{~min}$ utes at $94^{\circ} \mathrm{C}$, followed by a total of 40 cycles of two temperature cycles $\left(15\right.$ seconds at $95^{\circ} \mathrm{C}$ and 1 minute at $60^{\circ} \mathrm{C}$ ). Each sample was analyzed in triplicate and normalized to values for GAPDH mRNA expression using Taqman Rodent GAPDH Control Reagent (Applied Biosystems). Primers and probes labeled with carboxyfluorescein dye used in the experiments were as follows: OPN: 5'-TCCCTCGATGTCATCCCTGT-3' (forward), 5'-CCCTTTCCGTTGTTGTCCTG-3' (reverse), 5'CCCAGCTTCTGAGCATGCCCTCTG-3' (probe); CD68: 5' CAAGGTCCAGGGAGGTTGTG-3' (forward), 5' -CCAAAGGTAAGCTGTCCATAAGGA-3' (reverse), 5'-CGGTACCCATCCCCACCTGTCTCTCTC-3' (probe); MCP-1: 5'CAGCCAGATGCAGTTAACGC-3' (forward), 5' -GCCTACTCATTGGGATCATCTTG-3' (reverse), 5'-CCACTCACCTGCTGCTACTCATTCACCA-3' (probe); CCR-2: 5' -GCTCAACTTGGCCATCTCTGA-3' (forward), 5'-AGACCCACTCATTTGCAGCATA-3' (reverse), 5' ${ }^{\prime}$-TTCCTGCTCACATTACCATTCTGGGCTC-3' (probe); INF- $\gamma$ : $5^{\prime}$-AGCAACAGCAAGGCGAAAA-3' (forward), 5' $5^{\prime}$-CTGGACCTGTGGGTTGTTGA-3' (reverse), 5'-CCTCAAACTTGGCAATACTCATGAATGCATCC-3' (probe); IL-10: 5'-TTTGAATTCCCTGGGTGAGAA-3' (forward), 5'-ACAGGGGAGAAATCGATGACA-3' (reverse), 5' -TGAAGACCCTCAGGATGCGGCTG-3' (probe); IL-12 p40: 5'-ACCAGCTTCTTCATCAGGGACA-3' (forward), 5'-TCTTCAAAGGCTTCATCTGCAA-3' (reverse), $5^{\prime}$-CATCAAACCAGACCCGCCCAAGAA-3' (probe).

Analysis of aortic and leukocyte OPN expression. OPN mRNA expression in the thoracic aorta was analyzed by real-time RT-PCR 2 weeks after Ang II or vehicle infu- sion. Peritoneal leukocytes from male $\mathrm{OPN}^{+/+}$and $O P N^{-/-}$mice (aged 3 month, $n=3$ for each group) were elicited 2 weeks after Ang II or vehicle infusion by an intraperitoneal injection of $3 \mathrm{ml}$ of $3 \%$ Brewer's thioglycollate medium (Difco Laboratories, Detroit, Michigan, USA). Exudates were obtained 72 hours after injection by peritoneal lavage with PBS. Total RNA from these leukocytes was isolated and analyzed for OPN expression as described previously (31). Blots were cohybridized with cDNA encoding the constitutively expressed housekeeping gene $\mathrm{CHO}$ gene $\mathrm{B}(\mathrm{CHOB})$ to assess equal loading of samples. To selectively obtain macrophages, cells from the exudate were washed twice in sterile PBS and resuspended in RPMI-1640 medium supplemented with 5\% heat-inactivated FBS (Irvine Scientific, Santa Ana, California, USA) containing 100 $\mathrm{U} / \mathrm{ml}$ penicillin, $100 \mathrm{mg} / \mathrm{ml}$ streptomycin, and $2 \mathrm{mM}$ L-glutamine (Sigma-Aldrich, St. Louis, Missouri, USA). Cells were incubated at $37^{\circ} \mathrm{C}$ in an atmosphere of air containing $5 \% \mathrm{CO}_{2}$. Four hours after plating, nonadherent cells were removed by repeated washing with PBS. At least $96 \%$ of the adherent cells were Mac- $1^{+}$ macrophages. Viability of the cells was determined using trypan blue exclusion. To determine the dosedependent effect of Ang II on macrophage OPN expression, isolated peritoneal macrophages were serumdeprived for 24 hours in RPMI-1640 medium containing $0.4 \%$ FBS and stimulated with Ang II. Twenty-four hours after stimulation, RNA was isolated and analyzed for OPN expression by Northern blot analysis.

Chemotaxis assays. Chemotaxis assays were performed with peritoneal leukocytes in a modified Boyden chamber transwell migration assay as described previously (32). Briefly, $5 \times 10^{4}$ peritoneal leukocytes were plated in RPMI-1640 medium containing $0.4 \%$ FBS and incubated at $37^{\circ} \mathrm{C}$ for 1 hour, allowing the cells to attach. Basal migration and MCP-1-directed migration (50 $\mathrm{ng} / \mathrm{ml}$; R\&D Systems Inc., Minneapolis, Minnesota, USA) was determined after an 8-hour migration period. Nonmigrating cells were removed with a cotton tip, and cells were fixed and stained with a Quick-Diff stain set (Dade Diagnostics, Miami, Florida, USA). Cells that had undergone migration toward the lower compartment were counted per $\times 320$ high-power field (HPF) with the use of an Axiovert 135 microscope. Four randomly chosen HPFs were counted per membrane. Experiments were performed in triplicate and were repeated at least five times.

TUNEL assay and immunofluorescent staining. Apoptotic macrophages in atherosclerotic lesions were detected using an in situ Fluorescein-FragEL DNA fragmentation detection kit (Oncogene Research Products, Boston, Massachusetts, USA) according to the manufacturer's instructions. Briefly, serial $10-\mu \mathrm{M}$-thick cryosections of the ascending and thoracic aorta were permeabilized by proteinase $\mathrm{K}$ and incubated with deoxynucleotidyl transferase, which binds to exposed 3'-OH ends of DNA fragments and catalyzes the addition of fluorescein-labeled and unlabeled deoxynucleotides. 
After performing TUNEL assays, cryosections were blocked (1\% BSA, 1\% cold-water fish gelatin, $1 \mathrm{M}$ glycine, 3\% normal goat serum; Sigma-Aldrich) and stained with a rat anti-mouse Mac-3 mAb (1:50 dilution; BD Biosciences, San Diego, California, USA) for 1 hour, followed by an incubation of a secondary goat anti-rat IgG (1:200; Alexa Fluor 594 [Texas Red]; Molecular Probes Inc., Eugene, Oregon, USA). Apoptotic macrophages were analyzed by confocal microscopy and colocalization of fluorscein and Texas red staining after performing overlay projections. The percentage of positively stained macrophages was determined by counting the number of double-stained macrophages and total macrophages of five HPFs per cross-section $(n=4)$ from each mouse.

Peripheral blood counts, leukocyte recruitment, and leukocyte cell viability assays. Blood counts, quantitative and qualitative analysis of peritoneal exudates, and viability experiments were performed before and 4 weeks after infusion of $O P N^{+/+}$and $O P N^{-/-}$mice (aged 3 months; $n=4$ for each group) with Ang II or vehicle. Total peripheral white blood cell (WBC) counts were performed using a Coulter counter. Differential WBC counts were performed manually by a blinded and trained hematologist. Peritoneal leukocytes were elicited 4 weeks after infusion of Ang II or vehicle by intraperitoneal injection of $3 \mathrm{ml} \mathrm{3 \%}$ thioglycollate medium (Difco Laboratories) or after coinjection of 10 $\mu \mathrm{g}$ recombinant mouse OPN (R\&D Systems Inc., Minneapolis, Minnesota, USA) with thioglycollate medium. Exudates were obtained 72 hours after injection by peritoneal lavage with PBS. The total cell number per microliter of peritoneal exudate was counted using a hematocytometer. Qualitative composition of the peritoneal exudates was analyzed by labeling with primary mAb's against $\mathrm{Mac}-1^{+}$(macrophages) and $\mathrm{CD}^{+}(\mathrm{T}$ lymphocytes) (BD Biosciences) and performing flow cytometry using a FACScan (Becton Dickinson Immunocytometry Systems, San Jose, California, USA). Cell viability and apoptosis was analyzed by flow cytometry (Becton Dickinson Immunocytometry Systems) using a commercially available annexin V-FITC assay (Oncogene Research Products), according to the manufacturer's instructions. Western blot analysis for caspase- 3 was performed using a specific Ab for caspase- 3 as described previously (31). The polyclonal caspase- $3 \mathrm{Ab}$ detects endogenous levels of full-length caspase- 3 and the large fragment of caspase- 3 resulting from cleavage (9662, 1:1,000 dilution; Cell Signalling Technology, Beverley, Massachusetts, USA).

Zymography and MMP-2 Western immunoblotting. The aorta from $A p o E^{-/-} O P N^{+/+}$and $A p o E^{-/-} O P N^{-/-}$mice infused with Ang II or PBS ( $n=4$ for each group) was removed, pulverized by submersion in $\mathrm{LN}_{2}$, and incubated for 1 hour at $4^{\circ} \mathrm{C}$ in lysis buffer $(10 \mathrm{mmol} / 1$ sodium phosphate, $\mathrm{pH} 7.2$, containing $150 \mathrm{mmol} / 1$ $\mathrm{NaCl}, 1 \%$ Triton $\mathrm{X}-100,0.1 \%$ SDS, $0.5 \%$ sodium deoxycholate, and $0.2 \%$ sodium azide). After centrifugation, the protein concentration of the supernatant was determined, and equal amounts of total protein (10 $\mu \mathrm{g})$ were electrophoresed in $10 \%$ SDS-polyacrylamide gels containing $1 \mathrm{mg} / \mathrm{ml}$ gelatin (Sigma-Aldrich). Subsequently, SDS was removed from the gels by two washes (15 minutes) with $2.5 \%$ Triton X-100 (SigmaAldrich). Gels were incubated for 12 hours $\left(37^{\circ} \mathrm{C}\right)$ in zymography buffer (50 mmol/1 Tris ( $\mathrm{pH} \mathrm{8.0),} 10$ $\mathrm{mmol} / 1 \mathrm{CaCl}_{2}, 0.05 \%$ Brij 35), and stained with Coomassie brilliant blue. Recombinant mouse pro-MMP-2 and pro-MMP-9 (R\&D Systems Inc.) were activated in vitro by incubation with $p$-aminophenylmercuric acetate in a final concentration of 1 mM. Recombinant MMP-2 and MMP-9 (1 ng) were used as positive controls and for calibration. MMP-2 protein expression was analyzed by Western immunoblotting. Aortic tissue was homogenized in cell lysis buffer (Cell Signalling Technology) and cleared by centrifugation. Ten micrograms of protein was separated by SDS-PAGE under reducing conditions, blotted on nitrocellulose membranes, and incubated with a mAb to detect MMP-2 (RDI-MMP2abm-5D; Research Diagnostics Inc., Flanders, New Jersey, USA). One hundred nanograms of recombinant MMP-2 was used as positive control, and $100 \mathrm{ng}$ MMP-9 was employed to determine specificity.

Statistics. Data were expressed as mean plus or minus SEM. Statistical significance was determined using two-way ANOVA analysis and an unpaired Student $t$ test. $P$ values of less than 0.05 were considered statistically significant.

\section{Results}

Genetic knockout of OPN attenuates Ang II-accelerated atherosclerosis. To evaluate atherosclerotic lesion development in the Ang II-accelerated atherosclerosis model, 3 -month-old male $A p o E^{-/-} O P N^{+/+}$wild-type $(n=9)$, $A p o E^{-/-} O P N^{+/-}(n=9)$, and $A p o E^{-/-} O P N^{-/-}(n=6)$ littermate mice were placed on a regular chow diet and infused with $2.5 \mu \mathrm{g} / \mathrm{kg} / \mathrm{min}$ Ang II for 4 weeks. The abdominal segment was excluded from the atherosclerosis analysis because of the development of AAA after Ang II infusion and analyzed separately (25-27). Wild-type control mice infused with PBS exhibited either no or very few lesions in the aortic arch, as expected for the age of the mice. Ang II infusion promoted a significant increase in the extent of atherosclerosis in the arch and the thoracic aorta $(15.3 \% \pm 1.3 \%$; $n=9)$ compared with PBS-infused littermate controls $(0.3 \% \pm 0.01 \% ; n=9, P<0.01)$. In marked contrast, OPN-deficient mice demonstrated a substantial reduction of atherosclerotic lesions compared with littermate control mice (Figure 1, a and b), which was similar in heterozygote $A p o E^{-/-} \mathrm{OPN}^{+/-}(5.5 \% \pm 0.8 \%$; $n=9, P<0.01)$ and homozygote $A p o E^{-/-} O P N^{-/-}$ $(5.1 \% \pm 0.7 \% ; n=6, P<0.01)$ mice.

To evaluate whether there were any qualitative differences in lesions in addition to vessel lipid content, a histological and immunohistochemical analysis was performed (Figure 2). Analysis of the arterial tissue 
a
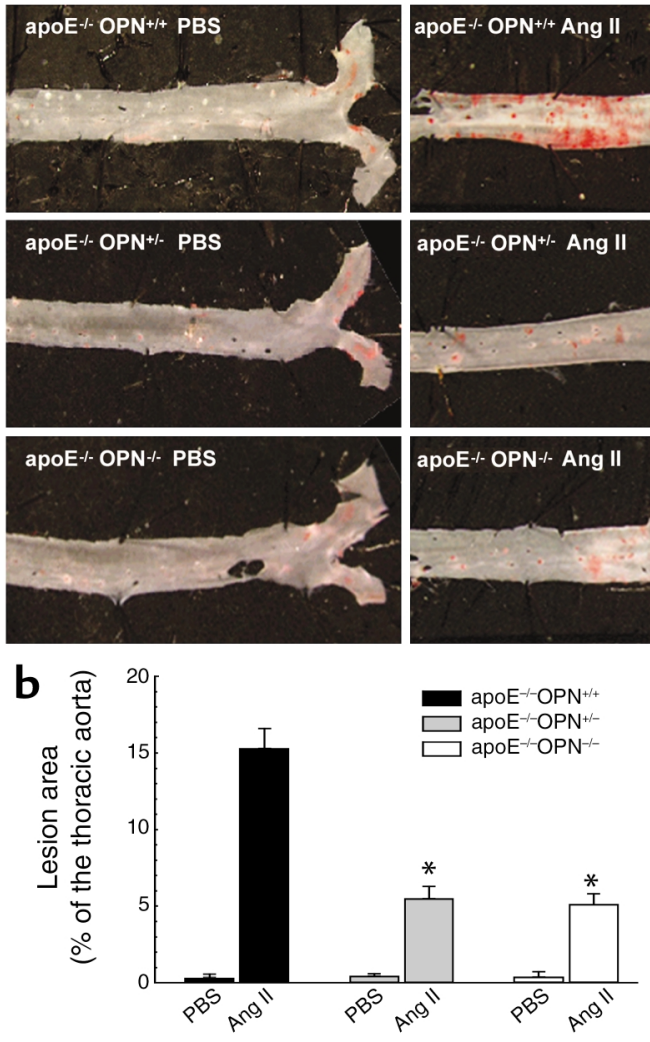

from Ang II-treated wild-type mice revealed predominantly fatty streak lesions (Figure 2a). Cores of these lesions consisted of lipid-laden macrophages at the boundary of the atherosclerotic intima and media that immunostained positively with the antimacrophage $\mathrm{Ab}$ (Figure $2 \mathrm{~b}$ ). In addition to fatty streak lesions, inflammation of the media was observed in $A \mathrm{PoE}^{-/-} \mathrm{OPN}^{+/+}$mice that correlated with immunoreactivity for macrophages within the media. In these fatty streak lesions and in the media of $\mathrm{ApoE}^{-/-} \mathrm{OPN}^{+/+}$ mice little immunoreactivity was observed for $\mathrm{T}$ lymphocytes (Figure 2c). In contrast, the $A p o E^{-/-} \mathrm{OPN}^{-/-}$ lesions were smaller, were strikingly less cellular (Figure $2 \mathrm{~d}$ ), and contained fewer foam cells. The arterial wall of $A \mathrm{PoE}^{-/-} \mathrm{OPN}^{-/-}$mice revealed less medial inflammation compared with the littermates and decreased immunoreactivity for macrophages (Figure $2 \mathrm{e})$. Breaks in the elastic lamina, which are a common feature of Ang II-enhanced lesion formation (26) were observed with equal frequency in $A P o E^{-/-} O P N^{-/-}$mice and $\mathrm{ApoE}^{-/-} \mathrm{OPN}^{+/+}$mice, however.

\section{Figure 2}

Immunohistochemical characterization of atherosclerotic lesions from $A p o E^{-/-} \mathrm{OPN}^{+/+}$and $A p o E^{-/-} \mathrm{OPN}^{-/-}$mice 4 weeks after Ang II infusion. Tissues of the thoracic aorta were analyzed by hematoxylin and eosin staining (a and $\mathbf{d}$ ) or immunohistochemical staining for the presence of macrophages ( $b$ and $\mathbf{e}$ ) and T lymphocytes ( $\mathbf{c}$ and $\mathbf{f}$ ) and counterstained with hematoxylin ( $\times 400$ magnification).

\section{Figure 1}

Ang II-accelerated atherosclerosis in male $A p o E^{-/-} \mathrm{OPN}^{+/+}$, $A p o E^{-/-} \mathrm{OPN}^{+/-}$, and $A p o E^{-/-} \mathrm{OPN}^{-/-} \mathrm{OPN}$ mice. Three-month-old mice on a regular chow diet were infused with vehicle or Ang II for 4 weeks. (a) En face analysis of aortae stained with Sudan IV to visualize accumulation of subintimal lipids present in atherosclerotic lesions. (b) Mean atherosclerotic lesion areas of the thoracic aorta from $A p o E^{-/-} \mathrm{OPN}^{+/+}$wild-type mice (black bars), $A p o E^{-/-} \mathrm{OPN}^{+/-}$ (gray bars), and $A p o E^{-/-} O P N^{-/-}$(white bars) mice determined by computer-assisted image analysis. Data are represented as average percentage of the total surface of the thoracic aorta and expressed as mean \pm SEM. ${ }^{*} P<0.05$ vs. $A p o E^{-/-} \mathrm{OPN}^{+/+}$infused with Ang II.

As shown in Table 1, there were no significant differences in plasma lipids, glucose, or insulin levels, or systolic blood pressures among littermate wild-type, $A p o E^{-1-} \mathrm{OPN}^{+/-}$, and $A p o E^{-/-} \mathrm{OPN}^{-/-}$mice after Ang II infusion. As a result of ApoE deficiency the total plasma cholesterol levels were elevated in all groups without significant differences in the three genotypes. OPN deficiency did not affect systolic blood pressures, which were $101 \pm 4 \mathrm{mmHg}$ in $A p o E^{-/-} \mathrm{OPN}^{+/+}$mice, $98 \pm 6$ $\mathrm{mmHg}$ in $A p o E^{-/-O P N^{+/-}}$mice, and $103 \pm 5 \mathrm{mmHg}$ in $A p o E^{-/-} \mathrm{OPN}^{-/-}$mice before Ang II infusion. All mice developed elevated systolic blood pressures in response

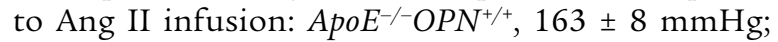
ApoE $E^{-/-} \mathrm{OPN}^{+/-}, 159 \pm 3 \mathrm{mmHg} ; \mathrm{ApoE}^{-/-} \mathrm{OPN}^{-/-}, 161 \pm 2$ $\mathrm{mmHg}$, compared with sham-infused animals at approximately $100 \mathrm{mmHg}$.

The influence of OPN on the development of atherosclerosis was next evaluated in 8-month-old male $A p o E^{-/-} \mathrm{OPN}^{+/+}$littermates and $A p o E^{-/-} O P N^{-/-}$mice on regular chow diet (Figure 3a). Older $A p o E^{-/-}$mice on

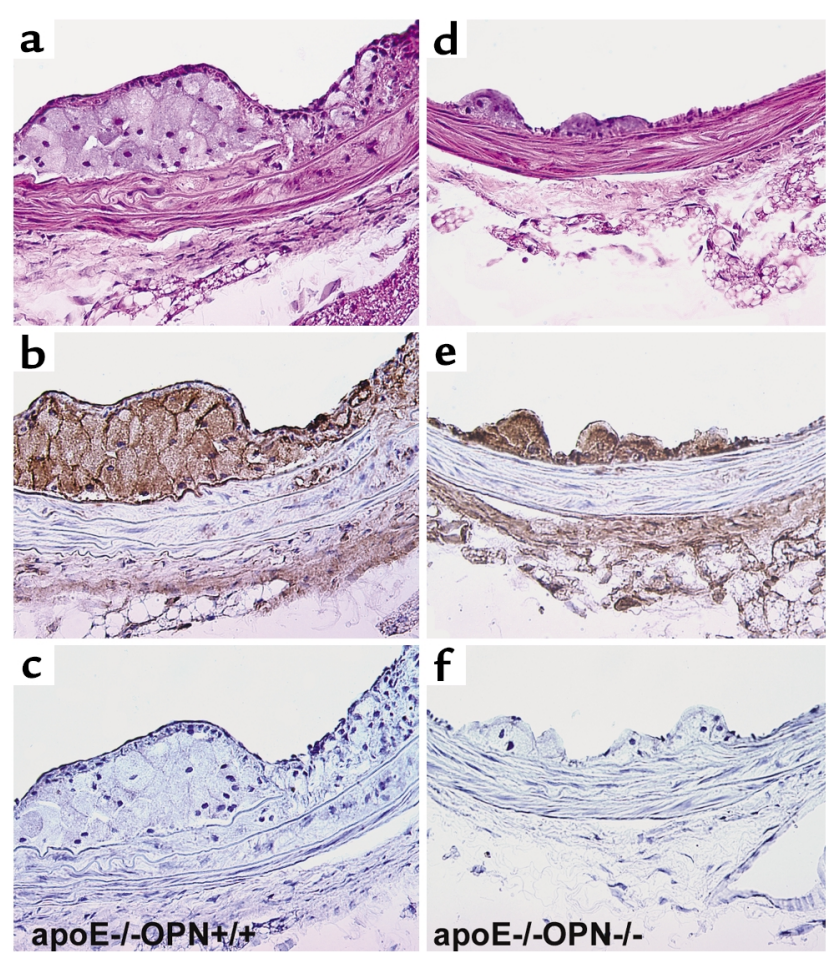


Table 1

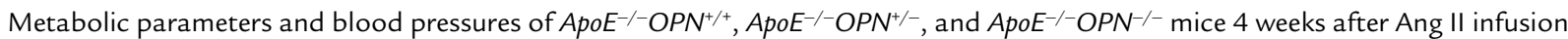

\begin{tabular}{|c|c|c|c|c|c|c|}
\hline \multirow[t]{2}{*}{ Group } & \multirow{2}{*}{$\begin{array}{l}\text { Triglycerides } \\
(\mathrm{mg} / \mathrm{dl})\end{array}$} & \multicolumn{2}{|c|}{ Cholesterol } & \multirow{2}{*}{$\begin{array}{l}\text { Glucose } \\
(\mathrm{ng} / \mathrm{ml})\end{array}$} & \multirow{2}{*}{$\begin{array}{l}\text { Insulin } \\
(\mathrm{mg} / \mathrm{dl})\end{array}$} & \multirow{2}{*}{$\begin{array}{r}\text { Systolic BP } \\
(\mathrm{mmHg})\end{array}$} \\
\hline & & Total (mg/dl) & $\mathrm{HDL}(\mathrm{mg} / \mathrm{dl})$ & & & \\
\hline$A p o E^{-/-} \mathrm{OPN}^{+/+}(n=9)$ & $67 \pm 6$ & $420 \pm 10$ & $31 \pm 9$ & $146 \pm 11$ & $654 \pm 46$ & $163 \pm 8$ \\
\hline$A p o E^{-/-} \mathrm{OPN}^{+/-}(n=9)$ & $67 \pm 14$ & $446 \pm 32$ & $38 \pm 7$ & $131 \pm 14$ & $661 \pm 36$ & $159 \pm 3$ \\
\hline$A p o E^{-/-} O P N^{-/-}(n=6)$ & $63 \pm 5$ & $447 \pm 22$ & $30 \pm 6$ & $156 \pm 30$ & $614 \pm 49$ & $161 \pm 2$ \\
\hline
\end{tabular}

Fasting plasma was obtained and evaluated for triglycerides, total plasma cholesterol, HDL cholesterol, and glucose and insulin levels. Systolic blood pressures were obtained from mice using a noninvasive tail-cuff system. Values are expressed as mean \pm SEM.

regular chow have been shown to develop substantial subintimal lipid accumulation (33). There was no significant difference in atherosclerotic lesion development between male $A p o E^{-/-} \mathrm{OPN}^{+/+}$and $\mathrm{ApoE}^{-/-} \mathrm{OPN}^{-/-}$ mice (Figure $3 \mathrm{~b}$ ). These studies indicate that hypercholesterolemia alone is not sufficient to trigger the proatherosclerotic effects of OPN. Thus, OPN is a critical factor differentiating and perhaps accounting for acceleration of atherosclerosis by Ang II.

Lenkocyte-derived OPN is critical for atherosclerosis development. In human atherosclerotic lesions, OPN is expressed by leukocytes as well as VCMCs and ECs (6). To further determine the cell-specific contribution of leukocyte-derived OPN to the decrease of Ang II-accelerated atherosclerosis in $A p o E^{-/-} \mathrm{OPN}^{-/-}$mice, 8-weekold male $A \mathrm{poE}^{-/-}$mice were irradiated and transplanted with bone marrow derived either from $\mathrm{ApoE}^{-/-} \mathrm{OPN}^{+/+}(n=7)$ or $A p o E^{-/-} \mathrm{OPN}^{-/-}(n=9)$ donors. Transplanted mice were fed a standard chow diet. Four weeks after transplantation, mice were infused with Ang II for 4 weeks, and their thoracic aortae were analyzed for atherosclerotic lesion area (Figure 4a). $\mathrm{ApoE}^{-/-}$ mice transplanted with $A p o E^{-/-} \mathrm{OPN}^{+/+}$bone marrow and infused with Ang II exhibited a similar extent of atherosclerosis as the unirradiated $A p o E^{-/-} \mathrm{OPN}^{+/+}$mice $\left(16.6 \% \pm 3.1 \%\right.$ lesion area; Figure 4b). When $A p o E^{-/-}$ mice received OPN-deficient bone marrow from $A p o E^{-/-} \mathrm{OPN}^{-/-}$mice, however, Ang II-accelerated atherosclerosis was reduced by $75.9 \%(4.0 \% \pm 1.0 \%$ lesion area versus $\left.A p o E^{-/-} O P N^{+/+}, P<0.05\right)$. These data indicate an important role for macrophage- and/or lymphocyte-derived OPN in the development of Ang IIaccelerated atherosclerosis.

Ang II induces OPN expression in the arterial wall and in murine macrophages. OPN expression is low in the normal arterial wall, and chronic Ang II infusion has been shown to induce arterial OPN expression in rat carotid arteries (21). Real-time RT-PCR from RNA samples obtained from the thoracic aorta 2 weeks after Ang II infusion confirmed that littermate wild-type control mice had low basal OPN levels. Ang II infusion resulted in a significant increase of aortic OPN mRNA expression (2.8-fold \pm 0.2 -fold versus PBS infusion, $P<0.05$; Figure 5a). Heterozygote $A P O E^{-/-} O P N^{+/-}$mice had $46 \%$ of the basal expression of $A \mathrm{POE}^{-/-} \mathrm{OPN}^{+/+}$mice, and the induction of vascular OPN by Ang II was reduced and did not reach significance (1.7-fold \pm 0.2 -fold versus PBS infusion, $P=0.058)$. OPN mRNA was not detectable in $A p o E^{-/-} \mathrm{OPN}^{-/-}$mice, confirming the phenotypic establishment of OPN deficiency in the $A p o E^{-/-}$background.

Because leukocyte-derived OPN appeared to be responsible for the exacerbated lesion development in Ang II-infused $A p o E^{-/-} \mathrm{OPN}^{-/-}$mice, we next investigated whether Ang II induces OPN mRNA expression in peritoneal leukocytes. Two weeks after vehicle or Ang II infusion, peritoneal leukocytes were isolated from $\mathrm{OPN}^{+/+}$mice ( $n=3$ for each group) and analyzed by Northern blotting for OPN mRNA expression. Ang II infusion into mice stimulated leukocyte OPN expression (3.1-fold \pm 0.3 -fold increase versus vehicle infusion, $P<0.005, n=3$; Figure $5 \mathrm{~b}$ ). In addition, peritoneal macrophages from $\mathrm{OPN}^{+/+}$mice were isolated and stimulated with Ang II ex vivo. Ang II dose dependently $(1 \mathrm{nM}-1 \mu \mathrm{M})$ induced macrophage OPN mRNA expression (Figure 5c).

a
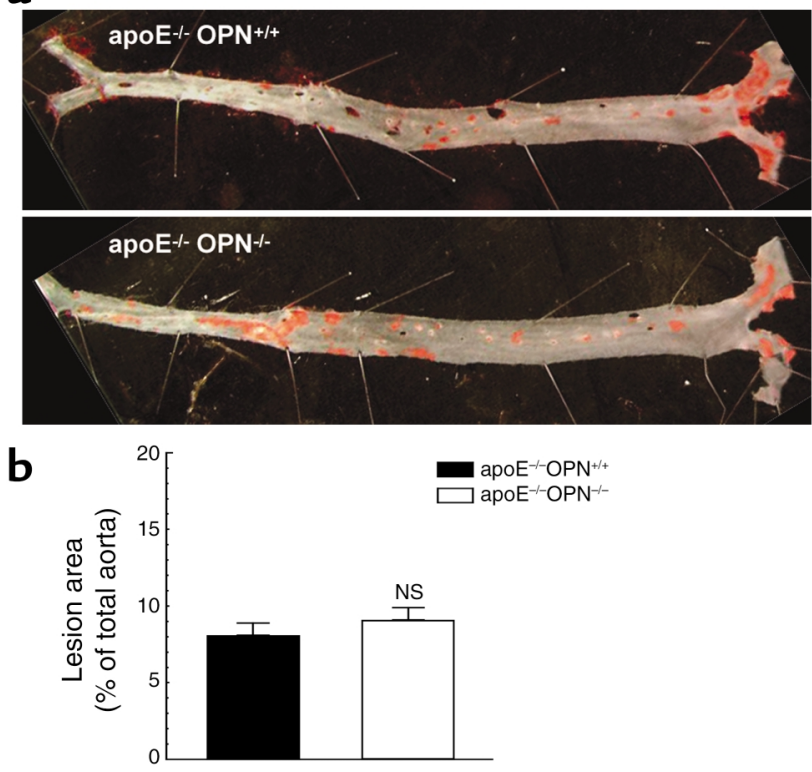

Figure 3

Atherosclerosis in non-Ang II-infused 8-month-old male

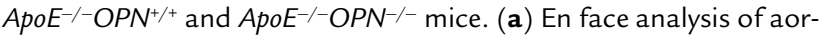
tic atherosclerosis in 8-month-old $A p o E^{-/-} \mathrm{OPN}^{+/+}$and $\mathrm{ApoE}^{-/-} \mathrm{OPN}^{-/-}$ mice on a regular chow diet. (b) Mean atherosclerosis development in the total aorta from $A p o E^{-/-} \mathrm{OPN}^{+/+}$(black bar) and $A p o E^{-/-} \mathrm{OPN}^{-/-}$ (white bar) mice analyzed as described in Figure 1. 
a
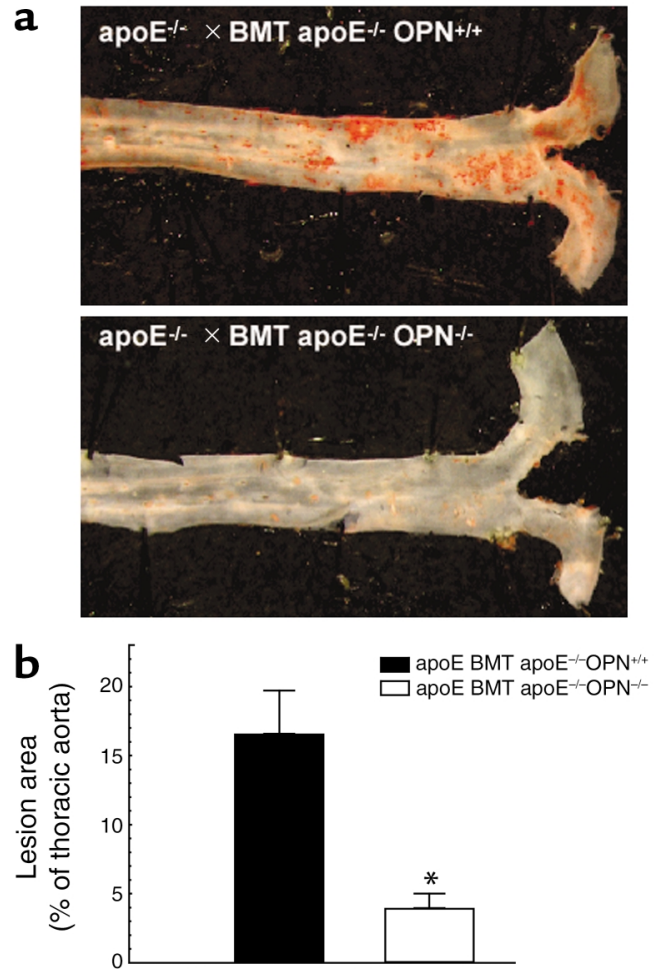

OPN mediates recruitment of macrophages and cytokine expression in Ang II-accelerated atherosclerosis. Infiltration of macrophages into the arterial intima constitutes one of the earliest events in the development of atherosclerosis $(19,34)$. Macrophage accumulation into the vessel wall was determined by quantitative real-time RT-PCR of CD68 mRNA expression. Acceleration of atherosclerosis with Ang II significantly induced CD68 mRNA expression in $A p o E^{-/-} \mathrm{OPN}^{+/+}$mice (5.9fold \pm 0 .3-fold induction versus PBS-infused littermate control mice, $P<0.05$; Figure 6a). In marked contrast, $A p o E^{-/-} \mathrm{OPN}^{+/-}$and $A \mathrm{PoE}^{-/-} \mathrm{OPN}^{-/-}$mice infused with Ang II exhibited no significant increase in CD68

\section{Figure 5}

OPN mRNA expression in Ang II-infused mice and murine macrophages. (a) Two weeks after infusion with vehicle or Ang II, OPN mRNA of the thoracic aorta from $\mathrm{ApoE}^{-/-} \mathrm{OPN}^{+/+}$(black bars), $A p o E^{-/-} O P N^{+/-}$(gray bars) and $A p o E^{-/-} / O P N^{-/-}$(white bars) mice was analyzed by quantitative real-time RT-PCR. Values are normalized for GAPDH expression and expressed as mean \pm SEM. ${ }^{*} P<0.05$ versus $A p o E^{-/-} \mathrm{OPN} N^{+/+}$mice infused with vehicle. (b) Two weeks after infusion with vehicle (PBS) or Ang II, peritoneal leukocytes from wild-type control mice ( $n=3$ in each group) were isolated after intraperitoneal injection of thioglycollate. Total RNA was analyzed for OPN expression by Northern blotting. Blots were cohybridized with cDNA encoding the constitutively expressed housekeeping gene $\mathrm{CHO}$ gene $\mathrm{B}(\mathrm{CHOB})$ to assess equal loading of samples. (c) Peritoneal macrophages were serum deprived for 24 hours and stimulated with increasing doses of Ang II. Twenty-four hours after stimulation, RNA was isolated and analyzed for OPN expression by Northern blotting. The autoradiograms shown are representative of three independently performed experiments.

\section{Figure 4}

Atherosclerosis in $A p o E^{-/-}$mice transplanted with $A p o E^{-/-} O P N^{+/+}$or $A p o E^{-/-} O P N^{-/-}$bone marrow. ApoE $E^{-/-}$mice were transplanted with either $A p o E^{-/-} \mathrm{OPN}^{+/+}$or $A p o E^{-/-} O P N^{-/-}$bone marrow and infused with Ang II for 4 weeks. (a) Representative Sudan IV-stained thoracic aorta of each analyzed group. (b) Mean atherosclerotic lesion area of $A p o E^{-/-}$mice transplanted with $A p o E^{-/-} \mathrm{OPN}^{+/+}$(black bar) or $A p o E^{-/-} O P N^{-/-}$(white bar) bone marrow. Data are represented as the average mean lesion area for each group and expressed as mean \pm SEM. ${ }^{*} P<0.05$ versus $A p o E^{-/-}$bone marrow-transplanted mice $A p o E^{-/-} O P N^{+/+}$. BMT, bone marrow transplanted.

mRNA in their vessels. Similar to CD68, Ang II-stimulated vascular CCR-2 expression was reduced in $A P o E^{-/-} \mathrm{OPN}^{+/-}$and $A P O E^{-/-} O P N^{-/-}$mice (Figure 6a).

Next, we analyzed MCP-1 mRNA expression, which is the primary chemoattractant for monocyte transendothelial migration during the early development of atherosclerosis $(35,36)$. Ang II infusion in littermate wild-type control mice promoted a 4.5 -fold \pm 0.3 -fold increase of MCP-1 mRNA expression (Figure 6a; $P<0.05$ versus $\mathrm{PBS}$-infused littermate control mice, $n=6)$. Surprisingly, Ang II-stimulated MCP-1 mRNA expression was higher in $A P O E^{-/-} \mathrm{OPN}^{+/-}$and $A p o E^{-/-} \mathrm{OPN}^{-/-}$mice $(P<0.05$ versus $P B S-i n f u s e d$ littermate control mice, $n=6$ ). Thus, despite the presence of a potent proinflammatory stimulus for monocytes to transmigrate, their recruitment into the arterial wall was dramatically decreased when OPN levels were reduced $50 \%$ or more in the homozygote and heterozygote mice. In addition, VCAM-1, an important adhesion molecule for monocytes, was analyzed. Ang II infusion induced VCAM-1 mRNA expression in the wild-type mice (4.0-fold \pm 0.7 -fold versus $P B S$, $P<0.05)$, which was abrogated in $A p o E^{-/-} \mathrm{OPN}^{+/-}$and $A P o E^{-/-O P N^{-/-}}$mice. It is possible that the decrease in VCAM-1 expression could contribute to decreased macrophage recruitment into the arterial wall. Decreased immigration of monocytes into the arterial 

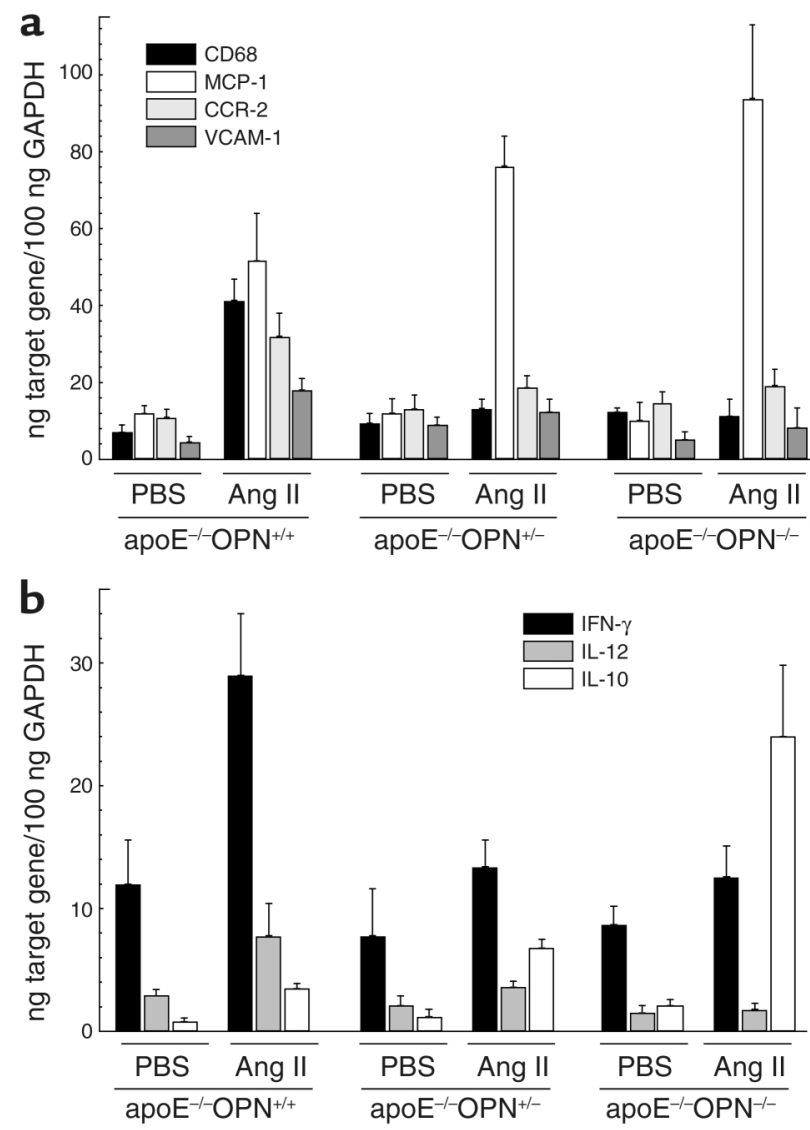

Figure 6

Expression of CD68, MCP-1, CCR-2, VCAM-1, and the cytokines INF- $\gamma$, IL-10, and IL-12 in Ang II-infused mice. ApoE $E^{-/-} \mathrm{OPN}^{+/+}$, $A p o E^{-/-} \mathrm{OPN}^{+/-}$, and $A p o E^{-/-} \mathrm{OPN}^{-/-}$mice were infused with vehicle or Ang II for 2 weeks. Tissue mRNA of the thoracic aorta was analyzed for CD68, MCP-1, CCR-2, and VCAM-1 (a) or INF- $\gamma$, IL-12, and IL-10 (b) mRNA expression. Data are normalized for GAPDH $m R N A$ expression and are represented as the average mean \pm SEM.

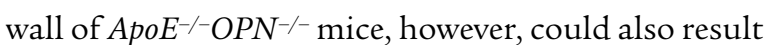
from modulation of other cytokines.

Cell-mediated immune responses in $\mathrm{OPN}^{-/-}$mice include diminished IL-12 and INF- $\gamma$ expression and increased IL-10 expression (37). Since these cytokines are involved in the pathogenesis of atherosclerosis (38-40), we investigated their mRNA expression in Ang II-infused wild-type and $A p o E^{-/-} O P N^{-/-}$vessels. Ang II infusion in littermates stimulated aortic INF- $\gamma$ mRNA expression, whereas $A p o E^{-/-} \mathrm{OPN}^{+/-}$and $A p o E^{-/-} \mathrm{OPN}^{-/-}$ mice exhibited reduced INF- $\gamma$ responses: 2.4 -fold \pm 0.4 fold induction in $\mathrm{ApoE}^{-/-} \mathrm{OPN}^{+/+}$mice in comparison with 1.7 -fold \pm 0.3 -fold and 1 .4-fold \pm 0.3 -fold induction in $A p o E^{-/-} \mathrm{OPN}^{+/-}$and $A p o E^{-/-} \mathrm{OPN}^{-/-}$mice $(P<0.05)$, respectively (Figure $6 \mathrm{~b}$ ). Similar results were obtained for mRNA levels of the IL-12 p40 subunit. Aortic IL-10 mRNA levels were induced by Ang II in littermates (4.4-fold \pm 0.5 -fold induction versus vehicle, $P<0.05$ ); however, IL-10 mRNA expression was substantially induced in $A p o E^{-/-} \mathrm{OPN}^{+/-}$and $\mathrm{ApoE}^{-/-} \mathrm{OPN}^{-/-}$mice (5.7-fold \pm 0 .6-fold and 11 .4-fold \pm 2 . 8 -fold induction versus vehicle, respectively; $P<0.005)$. These findings indicate that the regulation of leukocyte IL-12 and IL-10 expression during cell-mediated immunomechanisms reported previously in $O P N^{-/-}$mice (37) is comparable in response to atherogenic stimuli.

Migration of $\mathrm{OPN}^{-/-}$peritoneal lenkocytes is impaired. We next examined peritoneal leukocytes from $O P N^{+/+}$and $\mathrm{OPN}^{-/-}$mice for their ability to migrate in response to a chemotactic gradient of MCP-1. Other murine studies have validated assessment of peritoneal leukocyte migration as an effective method for the quantification of MCP-1-directed leukocyte migration (41). Basal migration of peritoneal leukocytes from $\mathrm{OPN}^{+/+}$ mice significantly increased in response to MCP-1 (Figure 7a). In contrast, heterozygote $\mathrm{OPN}^{+/-}$peritoneal leukocytes exhibited both impaired basal and chemoattractant-dependent migration. Even less basal migration was evident in homozygote $\mathrm{OPN}^{-/-}$leukocytes, which exhibited no chemotactic response to MCP-1. We next examined whether CCR-2 expression in $O P N^{-/-}$leukocytes is altered. As depicted in Figure $7 \mathrm{~b}, \mathrm{OPN}^{+/+}$and $O P N^{-/-}$leukocytes expressed comparable levels of CCR-2. Taken together, these results suggest that the reduction in MCP-1-directed migration of OPN-deficient leukocytes may be largely accounted for by a general inability to migrate rather than by alterations in the chemotactic axis.

$O P N$ promotes recruitment of leukocytes and increases cell viability. Although leukocyte migration is impaired in cells lacking OPN, OPN is expressed at low levels in monocytes, suggesting that vessel monocyte/macrophage accumulation may not only be due to a defect in adhesion or migration (42). To test whether there was a myelopoetic defect in $\mathrm{OPN}^{-/-}$mice, we examined peritoneal exudates and peripheral blood. We first deter-

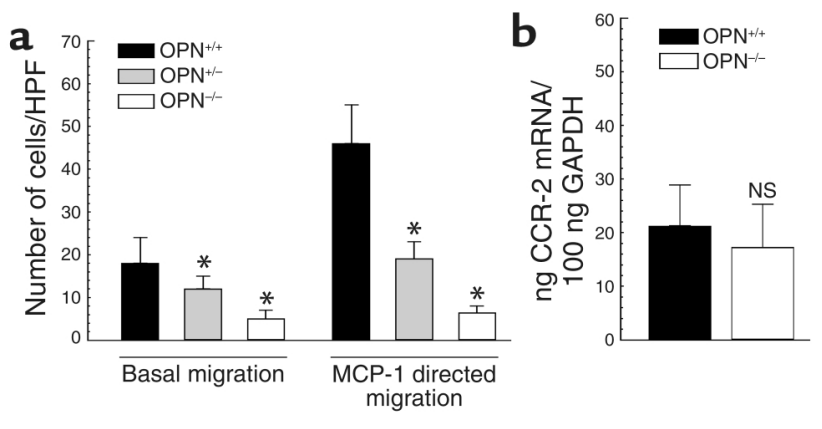

\section{Figure 7}

Transwell migration and CCR-2 expression of $\mathrm{OPN}^{+/+}$and $\mathrm{OPN}^{-/-}$ leukocytes. (a) Peritoneal leukocytes from $\mathrm{OPN}^{+/+}$and $\mathrm{OPN}^{-/-}$mice were harvested 3 days after thioglycollate injection and subjected to chemotaxis assays in modified Boyden chambers. Basal migration and MCP-1-directed migration $(50 \mathrm{ng} / \mathrm{ml}$ ) was determined and expressed as cell number counted per HPF $(\times 320)$. Experiments were repeated three times in duplicate. Data are expressed as mean \pm SEM, ${ }^{*} P<0.05$ versus $O P N^{+/+}$leukocytes. (b) CCR-2 mRNA expression was analyzed by quantitative real-time RT-PCR and normalized to GAPDH mRNA expression ( $n=4$ in each group). Data are represented as the average mean \pm SEM. 

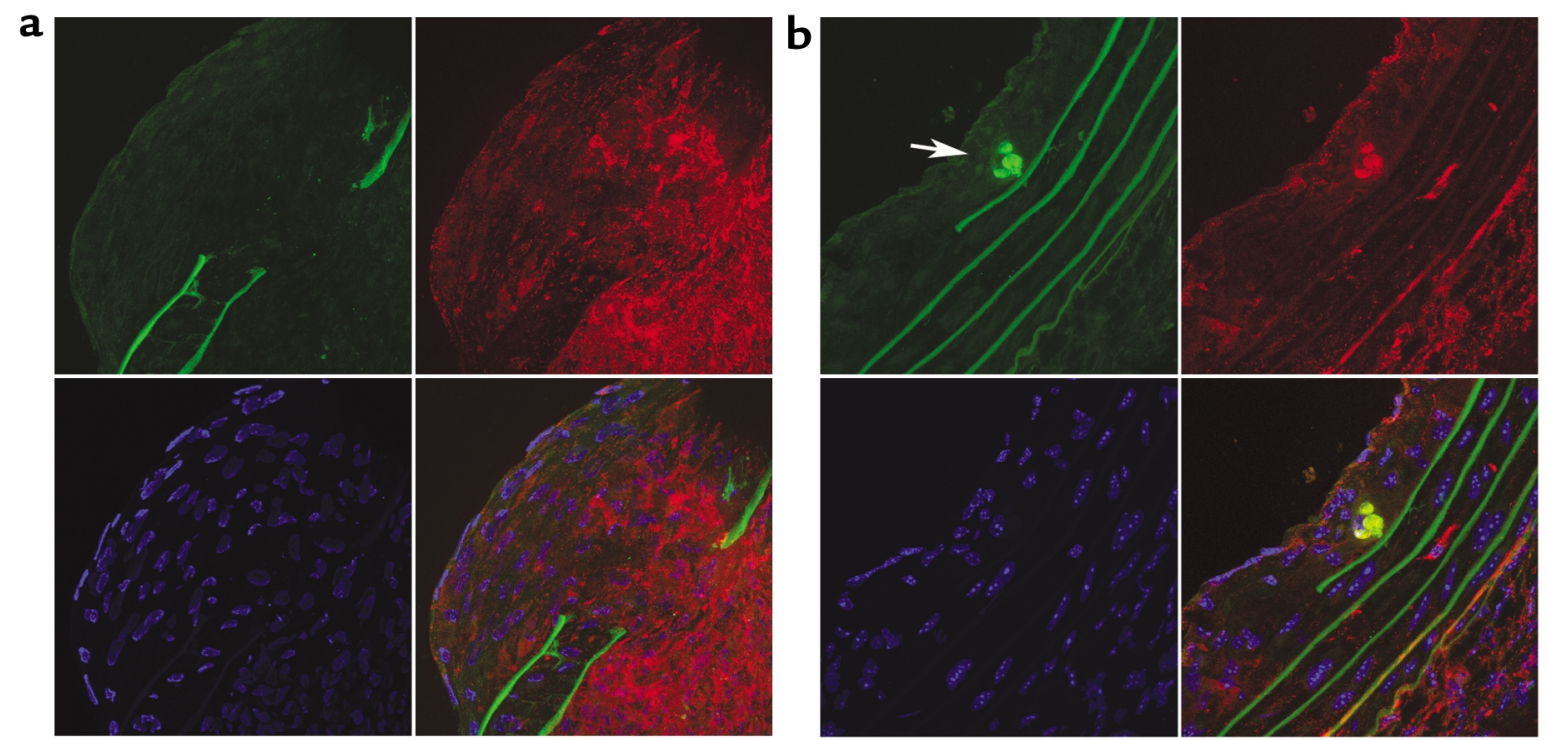

C
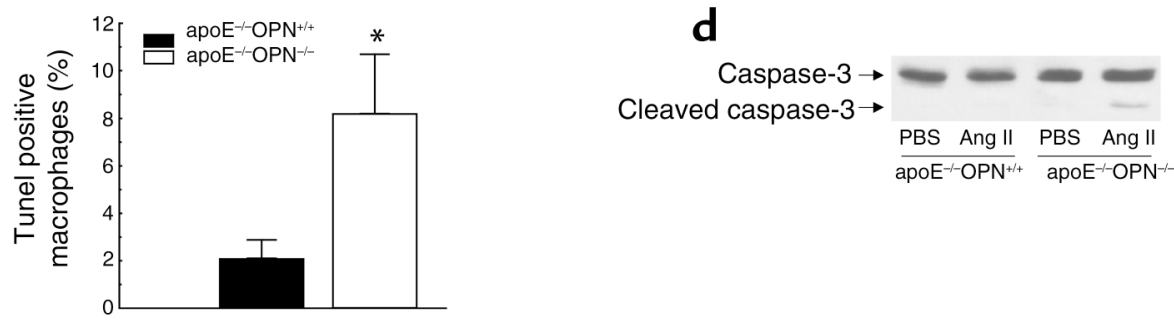

\section{Figure 8}

Decreased viability of $\mathrm{OPN}^{-1-}$ macrophages in atherosclerotic lesions. TUNEL staining of comparable-sized atherosclerotic lesions from Ang IIinfused $A p o E^{-/-} \mathrm{OPN}^{+/+}(\mathbf{a})$ and $A p o E^{-/-} O P N^{-/-}(\mathbf{b})$ mice. Cryostat sections were prepared and stained with TUNEL (green) as described in Methods. The elastic lamina of the vessel gives a prominent background staining allowing the detection of breaks as a common feature of Ang II infusion in $A p o E^{-/-}$mice. Sections were double stained with a rat anti-mouse Mac-3 mAb for the detection of macrophages (red) and DAPI (blue) to stain DNA. The overlay projection on the lower right of each picture allows the detection of colocalizing TUNEL macrophages (yellow). The arrow indicates typical examples ofTUNEL macrophages. (c) The percentage of positively stained macrophages was determined by counting the number of double-stained macrophages and total macrophages of five HPFs per cross section $(n=4)$ from each mouse $\left({ }^{*} P<0.05\right)$. (d) Representative Western immunoblot for aortic caspase-3 expression from $A p o E^{-/-} O P N^{+/+}$and $A p o E^{-/-} O P N^{-/-}$mice using an $\mathrm{Ab}$ detecting endogenous levels of full-length caspase-3 $(35 \mathrm{kDa})$ and the large fragment of caspase-3 resulting from cleavage (17 kDa).

mined total cell numbers in peritoneal exudates from $O P N^{+/+}$and $O P N^{-/-}$mice in response to thioglycollate with and without infusion of vehicle or Ang II for 4 weeks. The exudates from uninfused $O P N^{+/+}$mice contained $2,613 \pm 211$ cells $/ \mu \mathrm{l}$, while the exudates of $O P N^{-/-}$mice contained only 1,398 \pm 130 cells $/ \mu \mathrm{l}(n=5$, $P<0.001)$. Exudates from Ang II-infused $\mathrm{OPN}^{+/+}$and $O P N^{-/-}$tended to be slightly lower compared with uninfused controls, although this difference was not significant $(2,474 \pm 364, P=0.063$, and $1,189 \pm 167$, $P=0.072$, respectively). To determine whether the cellular composition of the exudates was different between $O P N^{+/+}$and $O P N^{-/-}$mice, exudates were analyzed by flow cytometry for macrophages (Mac-1) and $\mathrm{T}$ cells $\left(\mathrm{CD}^{+}\right)$. No significant differences in Mac-1-positive $(62.21 \% \pm 4.25 \%$ versus $61.95 \% \pm 2.35 \% ; n=5$, NS) or CD4-positive $(10.05 \% \pm 0.86 \%$ versus $8.20 \% \pm 0.66 \%$; $n=5$, NS) cells were observed between wild-type and $O P N^{-/-}$mice. These findings suggest that OPN deficiency is associated with a decreased number of inflammatory cells in the peritoneal exudates rather than a difference in composition compared with wild-type mice. These observations raised the question of whether lack of OPN affects the production of mononuclear cells in the bone marrow or the recruitment at sites of inflammation. To address this question we performed WBC counts in wild-type and $O P N^{-/-}$mice before and after Ang II infusion. There was no significant difference in total or differential WBC counts between $\mathrm{OPN}^{+/+}$ and $\mathrm{OPN}^{-/-}$mice (data not shown) before Ang II infusion. Since Ang II treatment might affect myelopoesis, we next analyzed total and differential WBC counts after infusion of Ang II for 4 weeks. Ang II infusion had no effect on total WBC counts or number of circulating monocytes, however, and there was no difference between wild-type (total WBCs: 5,500 \pm 984 leukocytes $/ \mu \mathrm{l}, 762 \pm 97$ monocytes $/ \mu \mathrm{l}$ ) and $O P N^{-/-}$mice (total WBCs: 5,300 \pm 300 leukocytes/ $\mu 1,709 \pm 65$ monocytes $/ \mu \mathrm{l})$. These data indicate that altered leukocyte production does not account for the profound reduction of macrophage recruitment in response to an inflammatory stimulus in OPN-deficient mice. 
OPN also functions as a cell survival factor and has been shown to prevent apoptosis in VSMCs, ECs, and pro-B cells (43-46). To determine macrophage viability in atherosclerotic lesions, we next performed TUNEL assays from comparable-sized lesions of Ang II-infused littermates and $A p o E^{-/-} O P N^{-/-}$mice. Double immunofluorescence staining demonstrated the presence of DNA fragmentation in lesions from Ang II-infused Apo $E^{-/-} O P N^{-/-}$mice, which colocalized with immunoreactivity for Mac-3, indicating decreased macrophage viability. Figure 8b shows typical examples of colocalizing TUNEL-positive (green) macrophages (red) in lesions from $A p o E^{-/-} O P N^{-/-}$mice. Quantitative analysis revealed that macrophage viability in lesions from $A p o E^{-/-} O P N^{-/-}$mice was markedly decreased compared with lesions from wild-type mice $(8.2 \% \pm 2.5 \%$ versus $2.1 \% \pm 0.8 \%, P<0.05$; Figure $8 \mathrm{c}$ ). In addition, Western immunoblot analysis confirmed increased levels of the enzymatically active $17-\mathrm{kDa}$ proteolytic cleavage product of the inactive $32-\mathrm{kDa}$ caspase- 3 precursor in aortae from Ang II-infused $A p o E^{-/-} O P N^{-/-}$mice (Figure $8 \mathrm{~d})$. These results indicate that decreased macrophage viability may be, in part, responsible for the decreased macrophage accumulation and atherosclerosis in Ang IIinfused $A p o E^{-/-} O P N^{-/-}$mice.

To determine whether leukocytes in peritoneal exudates from $O P N^{-/-}$mice are less viable, leukocytes from vehicle and Ang II-infused wild-type and $O P N^{-/-}$mice were analyzed by annexin $\mathrm{V}$ flow cytometry (Figure 9a). In addition, $O P N^{-/-}$mice were coinjected after Ang II infusion with recombinant mouse OPN and thioglycollate to evaluate whether exogenous OPN preserves leukocyte viability in OPN-deficient mice. In wild-type mice, infusion with Ang II resulted in a slight but significant decrease in leukocyte viability compared with vehicle, which was prevented by coinjecting recombinant OPN. Compared with wild-type mice, leukocytes from $O P N^{-/-}$mice infused with vehicle or Ang II showed significantly decreased viability, which was rescued by recombinant OPN. OPN-deficient leukocytes from vehicle-treated mice revealed proteolytic activation of caspase- 3 evidenced by the appearance of a $17-\mathrm{kDa}$ cleavage fragment (Figure 9b). $O P N^{-/}$leukocytes from Ang II-infused mice showed an increase in caspase-3 activation. Coinjection of recombinant OPN prevented proteolytic activation of caspase- 3 in both vehicle and Ang II-infused $O P N^{-/-}$mice. Thus, $O P N^{-/-}$leukocytes reveal decreased viability associated with increased caspase- 3 activation, suggesting that OPN triggers antiapoptotic signaling in leukocytes.

Ang II-induced abdominal aortic aneurysm formation is decreased in Apo $E^{-/-} O P N^{-/-}$mice. Ang II infusion into hypercholesterolemic atherosclerosis-prone mice has been demonstrated to induce the formation of AAA (25-27). To determine the effect of OPN deficiency on Ang II-induced aneurysm formation, we quantified their incidence and measured their sizes. Mice in which the increase in aortic diameter was less than $10 \%$ were not considered to have an aneurysm. Compared with littermate controls, $A p o E^{-/-} O P N^{-/-}$mice exhibited a dramatic reduction in the incidence of aneurysm formation (eight of nine $A p o E^{-/-} \mathrm{OPN}^{+/+}$mice developed aneurysms versus one of six for $A p o E^{-/-} O P N^{-/-}$; $P<0.005)$. In $A p o E^{-/-} O P N^{+/+}$mice that scored positive for aneurysm formation, the average diameter of the aorta increased $80 \%$. In the single $A p o E^{-/-} \mathrm{OPN}^{-/-}$that developed an aneurysm, the diameter increased $11 \%$. Figure 10, a and b, show representative aortae from $A p o E^{-/-} \mathrm{OPN}^{+/+}$and $A p o E^{-/-} \mathrm{OPN}^{-/-}$mice and EVG as well as elastin-trichrome staining from transversal sections. Aneurysm formation in wild-type mice was typically associated with a disruption of the media and breaks of the elastic lamina (Figure 10b).

Since aortic MMP activity has been implicated as an important mechanism associated with the development of aneurysms (47), we analyzed aortic MMP activity from vehicle- and Ang II-infused mice. In littermate wild-type mice aortic pro-MMP-2 activity was increased, as was MMP-2 and MMP-9 activity, at 4 weeks after Ang II infusion (Figure 10c). In contrast, in $A p o E^{-/-} \mathrm{OPN}^{-/-}$mice this increase was not observed. Western immunoblotting confirmed significant proMMP-2 and activated MMP-2 protein upregulation in

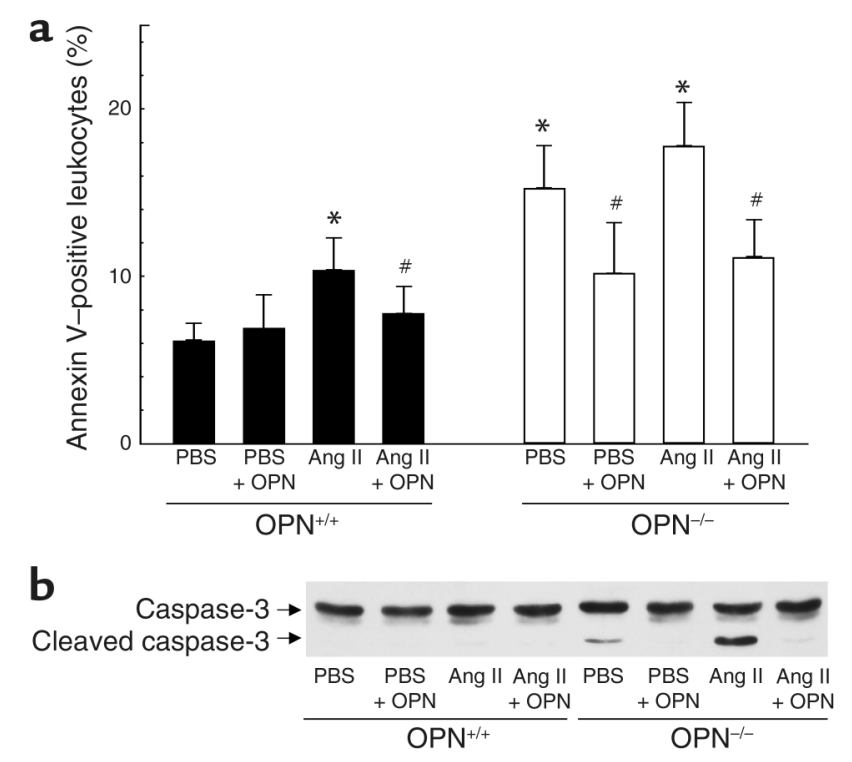

\section{Figure 9}

Decreased viability of peritoneal leukocytes from $O P N^{-1-}$ mice. Peritoneal $O P N^{+/+}$and $O P N^{-/-}$leukocytes were isolated 4 weeks after infusion with vehicle or Ang II by injection of thioglycollate alone or by coinjection with $10 \mu \mathrm{g}$ recombinant mouse OPN. (a) Leukocytes from $O P N^{+/+}$(black bars) and $O P N^{-/-}$(white bars) were stained with annexin V-FITC and analyzed by flow cytometry. Values are expressed as mean percentage of 10,000 counted cells \pm SEM. ${ }^{*} P<0.05$ versus $O P N^{+/+}$leukocytes from vehicle-infused mice, ${ }^{\#} P<0.05$ versus leukocytes from mice elicited by thioglycollate injection alone. (b) Protein extracts were analyzed by Western blot analysis for caspase3 cleavage using an Ab detecting endogenous levels of full-length caspase-3 $(35 \mathrm{kDa})$ and the large fragment of caspase-3 resulting from cleavage $(17 \mathrm{kDa})$. The autoradiogram shown is representative of three independently performed experiments. 

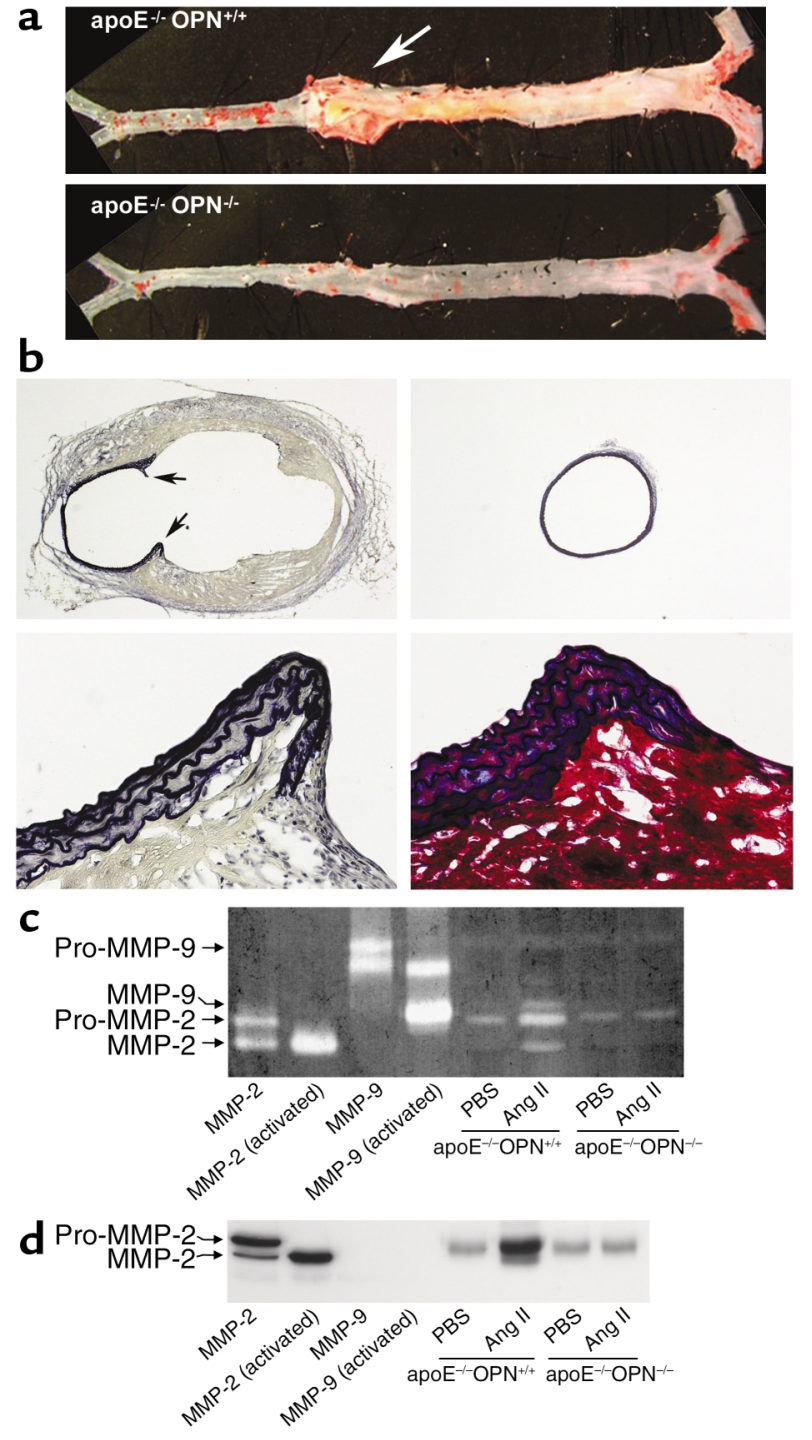

aortae of Ang II-infused littermate mice, which was blunted in $A p o E^{-/-} \mathrm{OPN}^{-/-}$mice (Figure 10d). Therefore, deficiency of OPN was associated with reduced incidence and severity of Ang II-induced aneurysm formation and decreased MMP-2 and MMP-9 activity.

\section{Discussion}

Although OPN participates in cellular immunity and inflammation and is expressed in atherosclerotic lesions, the specific contribution of OPN to the development of atherosclerosis and the related mechanisms are poorly understood $(6,48)$. Recent studies by Matsui et al. demonstrated that OPN deficiency decreases atherosclerosis development in female but not in male $A p o E^{-/-}$mice fed a normal chow diet (48). In an effort to further elucidate the role of OPN in accelerated atherosclerosis, we examined atherosclerosis development in $\mathrm{OPN}^{-/-}$mice crossed with atherosclerosis-prone $\mathrm{ApoE}^{-1-}$ mice and infused with Ang II, which profoundly accelerates atherosclerotic lesion development (25-27). The extent of Ang II-accelerat-

\section{Figure 10}

Decreased Ang II-induced abdominal aortic aneurysm formation and MMP-2 and MMP-9 activity in $A p o E^{-/-} O P N^{-/-}$mice. (a) Representative aorta from $A p o E^{-/-} \mathrm{OPN}^{+/+}$and $A p o E^{-/-} O P N^{-/-}$mice infused with Ang II for 4 weeks. The arrow indicates a typical abdominal aortic aneurysm in $A p o E^{-/-} \mathrm{OPN}^{+/+}$mice. (b) Characteristics of aneurysmal tissue from the abdominal aorta of $\mathrm{ApoE}^{-/-} \mathrm{OPN}^{+/+}$and $A p o E^{-/-} O P N^{-/-}$mice infused with Ang II. EVG staining of the elastic lamina (black) of $A p o E^{-/-} \mathrm{OPN}^{+/+}$(upper left) and $A p o E^{-/-} O P N^{-/-}$ (upper right) mice (both $\times 20$ magnification). The arrows indicate the disruption of the media and breaks of the elastic lamina. EVG (lower left) and trichrome (lower right) staining at higher power demonstrate the abdominal aortic wall of $\mathrm{ApoE}^{-/-} \mathrm{OPN}^{+/+}$mice containing smooth muscle cells (red) between elastic fibers (black) at the edge of the disrupted media. (c) Representative zymography analysis of MMP activities in the aorta from Ang II-infused $\mathrm{ApoE}^{-/-} \mathrm{OPN}^{+/+}$and $A p o E^{-/-} O P N^{-/-}$mice. Recombinant mouse MMP-2 and MMP-9 was activated by incubation with $p$-aminophenylmercuric acetate and used for calibration. (d) Representative Western blot analysis of aor-

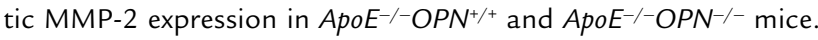
Recombinant MMP-2 and MMP-9 was used as positive control and for determination of specificity.

ed atherosclerosis in male heterozygote $A \mathrm{poE}^{-/-} \mathrm{OPN}^{+/-}$

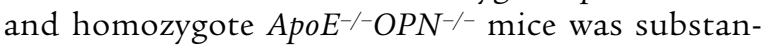
tially reduced compared with $A p o E^{-/-} O P N^{+/+}$mice. Consistent with the findings by Matsui et al., there was no difference in atherosclerotic lesion development in 8-month-old male mice fed a normal chow diet (48). These studies demonstrate that partial or complete lack of OPN is sufficient to abrogate the extensive inflammatory response associated with Ang IIaccelerated atherosclerosis. OPN deficiency, however, appears not to affect slower-progressing atherosclerosis in non-Ang II-infused male $A p o E^{-/-}$mice where hypercholesterolemia is a main trigger of the atherosclerotic process.

Activation of the RAS accelerates development of atherosclerosis and cardiovascular disease (22). Ang II functions as a potent proinflammatory stimulus and upregulates the expression of many redox-sensitive cytokines, chemokines, and growth factors involved in the pathogenesis of atherosclerosis, including OPN (21). The expression of OPN is also induced by high glucose, and OPN is highly expressed in atherosclerotic lesions of diabetic patients, suggesting that OPN may be involved in the pathogenesis of diabetic vascular complications and the accelerated atherosclerosis seen in diabetes $(7,8)$. Our observation that genetic OPN deficiency prevents the development of atherosclerosis in mice infused with Ang II but not in $A \mathrm{poE}^{-/-}$mice that are only hypercholesterolemic suggests that additional triggers are necessary for OPN to be atherogenic. Ang II, potentially combined with hyperglycemia in diabetes, may induce aortic OPN expression sufficient to promote vascular inflammation. Indeed, overexpression of OPN has been demonstrated to induce fatty streak lesions in mice (49) and enhanced vascular OPN expression may, therefore, emerge as a differentiating 
factor in accelerated atherosclerosis such as occurs in diabetes and the metabolic syndrome.

OPN is expressed by all cell types participating in vascular pathology (6). To determine the cell-specific contribution of OPN to the atherosclerotic process, we performed bone marrow transplantation studies. $A p o E^{-/-}$ mice were irradiated, reconstituted with either $A \mathrm{AoE}^{-/-} \mathrm{OPN}^{+/+}$ or $A p o E^{-/-} O P N^{-/-}$stem cells, and infused with Ang II. In this model, VSMC and EC OPN production was allowed to remain intact. Animals receiving stem cells with the full complement of OPN exhibited an extent of lesions similar to the unirradiated $A p o E^{-/-O P N^{+/+}}$mice, while those $A \mathrm{poE}^{-/-}$animals receiving the $\mathrm{ApoE}^{-/-} \mathrm{OPN}^{-/-}$ stem cells had a $76 \%$ reduction in lesion formation similar to the systemic OPN knockout animals. Therefore, leukocyte-derived OPN, rather than VSMCs or ECs, is necessary for Ang II to accelerate atherosclerosis.

Monocyte recruitment is clearly essential for both the formation of atherosclerosis and the generation of appropriate immune responses since knockout of MCP-1, or CCR-2, its cognate receptor on monocytes, prevents atherosclerosis development in genetically prone animals $(35,50)$ and results in decreased recruitment of peritoneal leukocytes in response to thioglycollate $(41,51)$. Decreased accumulation of macrophages in the arterial wall of $A p o E^{-/-} O P N^{-/-}$mice, as suggested by histologic analysis and evidenced by decreased aortic CD68 mRNA expression, indicated an important role for OPN in mediating the recruitment of macrophages into the arterial wall. Similar to the situation in MCP-1 and CCR-2 knockout mice (41, 51 ), injection of thioglycollate into the peritoneum of $O P N^{-/-}$mice was associated with decreased accumulation of peritoneal leukocytes. The latter observation is consistent with other in vivo studies in OPN-null mice, demonstrating impaired macrophage recruitment and function in cell-mediated immunity $(15,37,52,53)$. Given the possibility that decreased myelopoesis could account for a diminished immunity and leukocyte recruitment in $\mathrm{OPN}^{-/-}$mice, we analyzed WBC counts from $O P N^{-/-}$mice. The number of circulating monocytes, however, was not compromised in the presence of OPN deficiency and not affected by Ang II infusion. Thus, lack of OPN in bone marrow stem cells does not alter leukocyte production or their ability to enter the peripheral circulation.

OPN itself is a chemoattractant and previous reports have identified an important role for OPN in promoting adhesion and migration in a variety of cell lines in vitro, including macrophages $(11,14,54,55)$. Consistent with these reports, we observed decreased basal and MCP-1directed migration of $O P N^{-/-}$leukocytes, despite the fact that leukocyte CCR-2 mRNA levels in $O P N^{-/}$and $\mathrm{OPN}^{+/+}$were comparable. This implies that the reduced aortic CCR-2 expression in $A p o E^{-/-} \mathrm{OPN}^{-/-}$mice likely results from decreased accumulation of macrophages. MCP-1 is the major chemoattractant stimulus for monocytes to transmigrate into the subintimal interstitium (35). Ang II stimulates MCP-1 production in
VSMC and EC and thus promotes excess accumulation of macrophages leading to vascular inflammation (56). In $\mathrm{ApoE}^{-/-} \mathrm{OPN}^{+/+}$mice Ang II increased vascular expression of both MCP-1 and CD68. In contrast, in $A P o E^{-/-} \mathrm{OPN}^{-/-}$mice there was a profound reduction in CD68 expression, although MCP-1 expression, likely by VSMCs and ECs, was paradoxically increased. The cause of the paradoxical increase is unknown, however, but indicates an appropriate chemotactic stimulus. These data suggest that OPN is required for leukocyte migration and recruitment, and macrophages found in $A \mathrm{poE}^{-/-} \mathrm{OPN} N^{-/-}$atherosclerotic lesions, therefore, potentially may be resident macrophages.

In addition to the decreased ability of $O P N^{-/-}$leukocytes to transmigrate, modulation of other cytokines, such as IL-10, IL-12, and INF- $\gamma$, could contribute to a decrease in monocyte adhesion and macrophage accumulation in $A p o E^{-/-} \mathrm{OPN}^{-/-}$mice. The anti-inflammatory cytokine IL-10 prevents atherosclerosis by decreasing monocyte adhesion, and a previous report has shown that the decreased inflammatory response in $\mathrm{OPN}^{-/}$is in part mediated by decreased IL-12 and increased IL-10 levels $(37,40)$. In response to Ang II infusion ApoE-OPN $\mathrm{N}^{-/}$mice expressed substantially lower IL-12 and higher levels of IL-10 mRNA levels. In addition, vascular VCAM-1 expression in Ang IIinfused $A p o E^{-/-} \mathrm{OPN}^{-/-}$mice was lower compared with Apo $E^{-/-} \mathrm{OPN}^{+/+}$mice. Thus, decreased adhesion could contribute to the decreased vascular accumulation of macrophages in $A p o E^{-/-} \mathrm{OPN}^{-/-}$mice. Whether these changes in cytokine mRNA levels provide mechanistic insight or are a consequence of change in cell composition of the aortic wall, however, remains a subject for further studies.

OPN not only influences cell attachment, spreading, migration, and proinflammatory pathways, but also enhances cell survival and modulates phosphorylation of intracellular signal transduction intermediates such as focal adhesion kinase, paxillin, and Src (57). Several in vitro studies have shown that OPN protects cells from apoptosis induced by various stimuli $(44,46,52)$. Substantially fewer viable macrophages were found in atherosclerotic lesions from $A p o E^{-/-} \mathrm{OPN}^{-/-}$mice. Our data demonstrating that lack of OPN is associated with decreased viability of peritoneal leukocytes evidenced by increased annexin $\mathrm{V}$ binding and caspase- 3 cleavage, and that these changes are prevented by recombinant OPN, provides additional evidence for an important role of OPN in mediating antiapoptotic signaling and promoting cell survival in macrophages. Cell adhesion to ECM proteins is required for progression through the cell cycle and disruption of adhesion induces G1 arrest and apoptosis $(58,59)$. One signaling pathway that has been identified to regulate integrin-mediated cell survival is the nuclear NF- $\mathrm{KB}$ pathway, and binding of the ECs to OPN has been demonstrated to protect ECs from apoptosis via interaction with the integrin $\alpha_{v} \beta_{3}$ receptor resulting in activation of NF- $\mathrm{KB}(44)$. The precise signaling pathways by which OPN promotes cell survival 
require further investigation. Nevertheless, decreased macrophage viability resulting from lack of OPN appears to contribute to the decreased accumulation of macrophages at sites of inflammation in $\mathrm{OPN}^{-/-}$mice.

Inflammation of the arterial wall associated with the disruption of the orderly lamellar structure of the media appears to play a fundamental role in the development of Ang II-induced AAA formation. In $A p o E^{-/-} \mathrm{OPN}^{-/-}$mice the incidence and severity of Ang II-accelerated AAA formation was substantially reduced, suggesting that proinflammatory effects of OPN are not only involved in the development of atherosclerosis but also in AAA formation. Breaks in the medial elastic laminae of the artery as a potential basis for aneurysm formation are a common feature of Ang II infusion in $A p o E^{-/-}$mice (26). These breaks, however, were equally observed in Ang II-infused $A p o E^{-/-} \mathrm{OPN}^{-/-}$ mice, indicating other mechanisms responsible for the decreased occurrence of aneurysms in $A p o E^{-/-} \mathrm{OPN}^{-/-}$ mice. MMPs have been mechanistically implicated in the pathogenesis of AAA, in particular, MMP-2 and MMP-9 (47). Indeed, ApoE $E^{-/-} \mathrm{OPN}^{-/-}$mice exhibited decreased Ang II-induced vascular MMP-2 and MMP-9 activity, which may contribute to decreased formation of abdominal aneurysms.

In summary, the present investigation underscores a key role for leukocyte OPN in vascular pathology by mediating Ang II-accelerated atherosclerosis and aneurysm formation. Genetic OPN deficiency does not appear to alter monocyte production but is associated with decreased vascular macrophage accumulation due to decreased migration, macrophage viability, and proinflammatory cytokine expression. We conclude that OPN may be an important novel therapeutic target for the prevention and treatment of atherosclerosis and abdominal aneurysms.

\section{Acknowledgments}

We thank Longsheng Hong for excellent technical assistance in immunohistochemical procedures. This study was supported by NIH grant HL-70526 to Willa A. Hsueh. Dennis Bruemmer was supported by a grant from MSD Sharp \& Dohme (Acute Coronary Syndrome 2000) and by a fellowship from the Gonda (Goldschmied) Diabetes Center, University of California, Los Angeles.

1. O'Regan, A., and Berman, J.S. 2000. Osteopontin: a key cytokine in cellmediated and granulomatous inflammation. Int. J. Exp. Pathol. 81:373-390.

2. Denhardt, D.T., Giachelli, C.M., and Rittling, S.R. 2001. Role of osteopontin in cellular signaling and toxicant injury. Annu. Rev. Pharmacol. Toxicol. 41:723-749.

3. Franzen, A., and Heinegard, D. 1985. Isolation and characterization of two sialoproteins present only in bone calcified matrix. Biochem. J. 232:715-724.

4. Oldberg, A., Franzen, A., and Heinegard, D. 1986. Cloning and sequence analysis of rat bone sialoprotein (osteopontin) cDNA reveals an Arg-GlyAsp cell-binding sequence. Proc. Natl. Acad. Sci. U. S. A. 83:8819-8823.

5. Katayama, Y., et al. 1998. Casein kinase 2 phosphorylation of recombinant rat osteopontin enhances adhesion of osteoclasts but not osteoblasts. J. Cell Physiol. 176:179-187.

6. Giachelli, C.M., Liaw, L., Murry, C.E., Schwartz, S.M., and Almeida, M 1995. Osteopontin expression in cardiovascular diseases. Ann. N. Y. Acad. Sci. 760:109-126.
7. Takemoto, M., et al. 2000. Enhanced expression of osteopontin in human diabetic artery and analysis of its functional role in accelerated atherogenesis. Arterioscler. Thromb. Vasc. Biol. 20:624-628.

8. Bidder, M., et al. 2002. Osteopontin transcription in aortic vascular smooth muscle cells is controlled by glucose-regulated upstream stimulatory factor and activator protein-1 activities. J. Biol. Chem. 277:44485-44496.

9. Liaw, L., Almeida, M., Hart, C.E., Schwartz, S.M., and Giachelli, C.M. 1994. Osteopontin promotes vascular cell adhesion and spreading and is chemotactic for smooth muscle cells in vitro. Circ. Res. 74:214-224.

10. Hu, D.D., Hoyer, J.R., and Smith, J.W. 1995. Characterization of the interaction between integrins and recombinant human osteopontin. Ann. N. Y. Acad. Sci. 760:312-314

11. Weber, G.F., Ashkar, S., Glimcher, M.J., and Cantor, H. 1996. Receptorligand interaction between CD44 and osteopontin (Eta-1). Science. 271:509-512.

12. Gadeau, A.P., Campan, M., Millet, D., Candresse, T., and Desgranges, C. 1993. Osteopontin overexpression is associated with arterial smooth muscle cell proliferation in vitro. Arterioscler. Thromb. 13:120-125.

13. Nau, G.J., et al. 1997. A chemoattractant cytokine associated with granulomas in tuberculosis and silicosis. Proc. Natl. Acad. Sci. U. S. A. 94:6414-6419.

14. Giachelli, C.M., Lombardi, D., Johnson, R.J., Murry, C.E., and Almeida, M. 1998. Evidence for a role of osteopontin in macrophage infiltration in response to pathological stimuli in vivo. Am. J. Pathol. 152:353-358.

15. Liaw, L., et al. 1998. Altered wound healing in mice lacking a functional osteopontin gene (spp1). J. Clin. Invest. 101:1468-1478.

16. Patarca, R., Saavedra, R.A., and Cantor, H. 1993. Molecular and cellular basis of genetic resistance to bacterial infection: the role of the early T-lymphocyte activation-1/osteopontin gene. Crit. Rev. Immunol. 13:225-246.

17. O'Regan, A.W., et al. 1999. Osteopontin is associated with $\mathrm{T}$ cells in sarcoid granulomas and has $\mathrm{T}$ cell adhesive and cytokine-like properties in vitro. J. Immunol. 162:1024-1031.

18. Ross, R. 1999. Atherosclerosis is an inflammatory disease. Am. Heart J. 138:S419-S420.

19. Libby, P., et al. 1996. Macrophages and atherosclerotic plaque stability. Curr. Opin. Lipidol. 7:330-335.

20. Boullier, A., et al. 2001. Scavenger receptors, oxidized LDL, and atherosclerosis. Ann. N. Y. Acad. Sci. 947:214-222.

21. deBlois, D., et al. 1996. Angiotensin II induction of osteopontin expression and DNA replication in rat arteries. Hypertension. 28:1055-1063.

22. Unger, T. 2002. The role of the renin-angiotensin system in the development of cardiovascular disease. Am. J. Cardiol. 89:3A-9A.

23. Beckman, J.A., Creager, M.A., and Libby, P. 2002. Diabetes and atherosclerosis: epidemiology, pathophysiology, and management. JAMA. 287:2570-2581.

24. Plutzky, J., Viberti, G., and Haffner, S. 2002. Atherosclerosis in type 2 diabetes mellitus and insulin resistance: mechanistic links and therapeutic targets. J. Diabetes Complications. 16:401-415.

25. Daugherty, A., and Cassis, L. 1999. Chronic angiotensin II infusion promotes atherogenesis in low density lipoprotein receptor -/- mice. Ann. N. Y. Acad. Sci. 892:108-118.

26. Daugherty, A., Manning, M.W., and Cassis, L.A. 2000. Angiotensin II promotes atherosclerotic lesions and aneurysms in apolipoprotein Edeficient mice. J. Clin. Invest. 105:1605-1612.

27. Weiss, D., Kools, J.J., and Taylor, W.R. 2001. Angiotensin II-induced hypertension accelerates the development of atherosclerosis in ApoEdeficient mice. Circulation. 103:448-454.

28. Collins, A.R., et al. 2001. Troglitazone inhibits formation of early atherosclerotic lesions in diabetic and nondiabetic low density lipoprotein receptor-deficient mice. Arterioscler. Thromb. Vasc. Biol. 21:365-371.

29. Daugherty, A., Manning, M.W., and Cassis, L.A. 2001. Antagonism of AT2 receptors augments angiotensin II-induced abdominal aortic aneurysms and atherosclerosis. Br. J. Pharmacol. 134:865-870.

30. Shih, D.M., et al. 2000. Combined serum paraoxonase knockout/ apolipoprotein E knockout mice exhibit increased lipoprotein oxidation and atherosclerosis. J. Biol. Chem. 275:17527-17535.

31. Bruemmer, D., et al. 2003. Peroxisome proliferator-activated receptor gamma inhibits expression of minichromosome maintenance proteins in vascular smooth muscle cells. Mol. Endocrinol. 17:1005-1018.

32. Kintscher, U., et al. 2000. Peroxisome proliferator-activated receptor and retinoid $\mathrm{X}$ receptor ligands inhibit monocyte chemotactic protein-1directed migration of monocytes. Eur. J. Pharmacol. 401:259-270.

33. Zhang, S.H., Reddick, R.L., Piedrahita, J.A., and Maeda, N. 1992. Spontaneous hypercholesterolemia and arterial lesions in mice lacking apolipoprotein E. Science. 258:468-471.

34. Glass, C.K., and Witztum, J.L. 2001. Atherosclerosis. the road ahead. Cell. 104:503-516.

35. Gu, L., et al. 1998. Absence of monocyte chemoattractant protein-1 reduces atherosclerosis in low density lipoprotein receptor-deficient mice. Mol. Cell. 2:275-281. 
36. Gosling, J., et al. 1999. MCP-1 deficiency reduces susceptibility to atherosclerosis in mice that overexpress human apolipoprotein B.J. Clin. Invest. 103:773-778.

37. Ashkar, S., et al. 2000. Eta-1 (osteopontin): an early component of type-1 (cell-mediated) immunity. Science. 287:860-864.

38. Uyemura, K., et al. 1996. Cross-regulatory roles of interleukin (IL)-12 and IL-10 in atherosclerosis. J. Clin. Invest. 97:2130-2138.

39. Gupta, S., et al. 1997. IFN-gamma potentiates atherosclerosis in ApoE knock-out mice. J. Clin. Invest. 99:2752-2761.

40. Pinderski Oslund, L.J., et al. 1999. Interleukin-10 blocks atherosclerotic events in vitro and in vivo. Arterioscler. Thromb. Vasc. Biol. 19:2847-2853.

41. Boring, L., et al. 1997. Impaired monocyte migration and reduced type 1 (Th1) cytokine responses in C-C chemokine receptor 2 knockout mice. J. Clin. Invest. 100:2552-2561.

42. Atkins, K., et al. 1998. Coordinate expression of OPN and associated receptors during monocyte/macrophage differentiation of HL-60 cells. J. Cell Physiol. 175:229-237.

43. Weintraub, A.S., Schnapp, L.M., Lin, X., and Taubman, M.B. 2000. Osteopontin deficiency in rat vascular smooth muscle cells is associated with an inability to adhere to collagen and increased apoptosis. Lab. Invest. 80:1603-1615

44. Scatena, M., et al. 1998. NF-kappaB mediates alphavbeta3 integrininduced endothelial cell survival. J. Cell Biol. 141:1083-1093.

45. Rittling, S.R., Chen, Y., Feng, F., and Wu, Y. 2002. Tumor-derived osteopontin is soluble, not matrix associated. J. Biol. Chem. 277:9175-9182.

46. Lin, Y.H., et al. 2000. Coupling of osteopontin and its cell surface receptor CD44 to the cell survival response elicited by interleukin-3 or granulocyte-macrophage colony-stimulating factor. Mol. Cell Biol. 20:2734-2742.

47. Longo, G.M., et al. 2002. Matrix metalloproteinases 2 and 9 work in concert to produce aortic aneurysms. J. Clin. Invest. 110:625-632. doi:10.1172/JCI200215334.
48. Matsui, Y., et al. 2003. Osteopontin deficiency attenuates atherosclerosis in female apolipoprotein E-deficient mice. Arterioscler. Thromb. Vasc. Biol. 23:1029-1034.

49. Isoda, K., et al. 2003. Osteopontin transgenic mice fed a high-cholesterol diet develop early fatty-streak lesions. Circulation. 107:679-681.

50. Boring, L., Gosling, J., Cleary, M., and Charo, I.F. 1998. Decreased lesion formation in CCR2-/- mice reveals a role for chemokines in the initiation of atherosclerosis. Nature. 394:894-897.

51. Lu, B., et al. 1998. Abnormalities in monocyte recruitment and cytokine expression in monocyte chemoattractant protein 1-deficient mice. J. Exp. Med. 187:601-608.

52. Ophascharoensuk, V., et al. 1999. Obstructive uropathy in the mouse: role of osteopontin in interstitial fibrosis and apoptosis. Kidney Int. 56:571-580.

53. Nau, G.J., et al. 1999. Attenuated host resistance against Mycobacterium bovis BCG infection in mice lacking osteopontin. Infect. Immun. 67:4223-4230.

54. Yamamoto, S., et al. 1995. Effect of recombinant osteopontin on adhesion and migration of P388D1 cells. Ann. N. Y. Acad. Sci. 760:378-380.

55. Nasu, K., et al. 1995. Expression of wild-type and mutated rabbit osteopontin in Escherichia coli, and their effects on adhesion and migration of P388D1 cells. Biochem. J. 307:257-265.

56. Chen, X.L., Tummala, P.E., Olbrych, M.T., Alexander, R.W., and Medford, R.M. 1998. Angiotensin II induces monocyte chemoattractant protein-1 gene expression in rat vascular smooth muscle cells. Circ. Res. 83:952-959.

57. Denhardt, D.T., et al. 1995. Osteopontin-induced modifications of cellular functions. Ann. N. Y. Acad. Sci. 760:127-142.

58. Meredith, J.E., Jr., Fazeli, B., and Schwartz, M.A. 1993. The extracellular matrix as a cell survival factor. Mol. Biol. Cell. 4:953-961.

59. Fang, F., Orend, G., Watanabe, N., Hunter, T., and Ruoslahti, E. 1996. Dependence of cyclin E-CDK2 kinase activity on cell anchorage. Science. 271:499-502. 